\title{
ECONOMICS
}

\section{THE COST OF DISPLACING FOSSIL FUELS: SOME EVIDENCE FROM TEXAS}

\author{
by \\ Peter R. Hartley \\ Department of Economics and \\ Center for Energy Studies, James A. Baker III Institute for \\ Public Policy Rice University \\ and \\ Business School, University of Western Australia
}




\title{
The cost of displacing fossil fuels: Some evidence from Texas
}

\author{
Peter R. Hartley* \\ Department of Economics and \\ Center for Energy Studies, James A. Baker III Institute for Public Policy \\ Rice University \\ and \\ Department of Economics, University of Western Australia
}

\begin{abstract}
Fossil fuels will be displaced as depletion raises their explicit costs, but may be displaced sooner if they are taxed in order to internalize negative externalities. Currently, wind generation or nuclear power, supplemented by bulk electricity storage, are the most feasible alternatives to fossil fuels for electricity generation. The ERCOT ISO transmission grid in Texas provides a realistic model for examining the costs of replacing fossil fuels by wind generation and storage, and to compare wind power with generation based on nuclear and storage. ERCOT is relatively isolated from neighboring grids, and wind power was almost a quarter of its total generating capacity at the end of 2016. Using the ERCOT example, we also discuss how the long-run configuration of the electricity supply system affects evolution away from a system dominated by natural gas.
\end{abstract}

Key words: Energy transition, wind, nuclear, natural gas, electricity storage

JEL Codes: D92, L94, Q42, Q54, Q55

${ }^{*}$ I thank Michael Maher in the Center for Energy Studies, James A. Baker III Institute for Public Policy at Rice University, Raúl Bajo-Buenestado of the University of Navarra, Ken Clements at the University of Western Australia and other seminar participants for valuable comments. 


\section{Introduction}

According to the International Energy Agency (IEA) key world energy statistics, fossil fuels supplied about $81 \%$ of the world's primary energy in 2014. Although the growth in renewable energy sources, especially wind generation, has been strong for at least the last 15 years, more than $92 \%$ of the non-fossil component of primary energy in 2014 was supplied by nuclear, hydroelectricity and biomass. Most forecasts have fossil fuels continuing to dominate primary energy supply for many decades to come. Nevertheless, depletion will raise the costs of fossil fuel resources and ultimately make them uncompetitive. Taxes imposed on fossil fuel use to compensate for negative externalities associated with their production and combustion will hasten their displacement.

The energy technology that will likely be used when fossil fuels are no longer dominant is of interest for several reasons. In a dynamic optimization context, and given the long lifetime of most energy infrastructure, the likely long-run configuration of the energy supply system influences optimal investments and policy decisions in earlier periods back to today. The cost of the alternative "backstop" energy supply to fossil fuels is also important. The higher that cost, the longer will fossil fuels remain viable as an energy source. Furthermore, with the cost of fossil fuels generally rising as they are depleted, a higher cost of energy at the time of transition implies that more total fossil fuels will have been used by then regardless of the prior trajectory of fossil use. Finally, as argued by Hartley et al. [8], and verified again in Hartley and Medlock [9], a higher cost of the backstop technology will imply there is more of an "energy crisis" around the transition time. The crisis is characterized by slower economic growth and a drop in the consumption/output ratio as more resources are devoted to investing in energy technologies and procuring energy inputs into final production. ${ }^{1}$

The evolution of the power generation part of the overall energy supply system will play a central role in the transition away from fossil fuels. While the transportation sector consumes about one quarter of total final energy (again according to IEA statistics), electricity is the most likely alternative to oil products for ground transportation. ${ }^{2}$ Electricity can also substitute for fossil fuels in providing heating services. Hence, as argued by Green and Staffell [4] for example, the electricity sector is at the forefront of any move to displace fossil fuels. ${ }^{3}$

\footnotetext{
${ }^{1}$ While this discussion is framed in the context of a rising cost of fossil fuels as they are depleted, as shown by Hartley and Medlock [9], for example, the situation is not fundamentally different if investment in energy technologies can lower the cost of the backstop and/or delay the rise in fossil fuel costs as they are depleted.

${ }^{2}$ The alternative to oil-based products for powering aircraft is less obvious.

${ }^{3}$ Boßmann and Staffell [1] point out that using electricity to supply transportation and heating demand will likely change the shape of the load curve. While our analysis is based on data on actual hourly wind output and load rather than a hypothetical forecast load curve, it would be of interest to repeat the exercise under different assumptions about how the daily load curve might evolve as electricity supplies additional sources of energy demand.
} 
Within the electricity sector, renewable energy supplies, and especially wind power, are seen as critical to allowing power generation without fossil fuels. ${ }^{4}$ In order to evaluate the potential of wind generation for this role, the Electricity Reliability Council of Texas (ERCOT) ISO is of particular interest. The more than $18 \mathrm{GW}$ of wind capacity in ERCOT at the end of 2016 was more than $24 \%$ of total generation capacity. Wind generators also supplied slightly more than $15 \%$ of the ERCOT load in 2016. Furthermore, ERCOT has weak links and little trade in electricity with neighboring systems. Thus, the ERCOT experience can be used to judge how scaling up wind generation to replace fossil fuel generation may affect system costs.

Wind generation suffers from the problems that it fluctuates substantially over short intervals, produces no output when wind speeds are too low or too high, cannot be dispatched always and only when needed, and tends to be low during periods of peak demand. Effective electricity storage could solve all of these problems and allow wind to supply $100 \%$ of needed generation. We ask whether the combination of wind power and storage is likely to be the least costly way to replace fossil fuels in electricity generation.

\section{Related literature}

Our analysis is related to several lines of research. Most directly, it is concerned with the long-run evolution of the energy supply system and what might constitute the "backstop technologies" to replace fossil fuels. In a pair of articles, Jacobson and Delucchi ([3] and [10]) examine the feasibility and potential cost of satisfying global energy demand using wind, water and solar generation. In order to compensate for the non-dispatchability of most of these sources, they propose supplementing the system with hydropower and battery and hydrogen storage, real time prices to shift demand to when more of the electricity is being generated, and additional transmission lines to reduce correlation in output from renewable generators. They claim that their system would be similar in cost to the predominantly fossil fuel based system in use today.

Trainer [15] argued that Jacobson and Delucchi did not realistically evaluate the costs of coping with variability in the supply of renewable energy. He noted that wind speeds that are either too high or too low can both reduce wind output almost to zero. He presented data showing that in many electricity systems with substantial wind capacity there can be several successive days with wind generators operating at load factors well below $10 \%$. He also questions

\footnotetext{
${ }^{4}$ For example, many states in the United States have introduced renewable energy mandates aimed at reducing fossil fuel use. In most cases, hydroelectricity and nuclear power are not counted as "renewable" and most of the capacity added under the mandates has been wind. Although the cost of utility-level solar power has been falling, it is still considerably more expensive than wind. Texas has recently encouraged more utility-level solar power projects, but as of the end of 2015 total capacity was under 600MW. Data on the performance of the solar farms in Texas is less readily available than data on wind farms.
} 
the claim of Jacobson and Delucchi that a more extensive grid, harvesting wind from a large geographic area, can obviate the need for storage in a system dominated by wind generation. He cites data from Australia, for example, showing that for " $20 \%$ of the time a wind system integrated across $1500 \mathrm{~km}$ from Adelaide to Brisbane would be operating at under $8 \%$ of peak capacity."

When a large amount of backup capacity is added to the system to cope with low wind output, it tends to operate at a low load factor since it is not used when wind output is high. In addition, there is a complementary problem when wind speed is ideal. Too much electricity is generated and discarding it will reduce the overall load factor on wind generators. Trainer then argues that the proposals of Jacobson and Delucchi to overcome these problems through storage seriously understate the costs of building and operating bulk electricity storage systems.

Jacobson and Delucchi [10] ruled out nuclear power as a replacement for fossil fuels on grounds other than economics - primarily that widespread use of nuclear power would increase the proliferation of nuclear weapons. They also claim that nuclear would be less effective than wind at reducing $\mathrm{CO}_{2}$ emissions. Qvist and Brock [13] take the opposite view that nuclear power is one of the few base load alternatives to fossil fuel that is currently available and which historical experience has proved can be significantly expanded and scaled up to allow deep cuts in $\mathrm{CO}_{2}$ emissions. They use data from Sweden's rapid expansion of nuclear power between 1960 and 1990 to demonstrate the ability of nuclear power to reduce $\mathrm{CO}_{2}$ emissions while simultaneously allowing substantial economic growth. They also claim that the Swedish experience demonstrates that nuclear could replace global fossil fuel generation capacity in around two decades. Using data from France, they increase this estimate to about 34 years.

Grubler [7] presented data on the French nuclear build-up that leads to less optimistic conclusions. He points out that construction times and costs escalated as the French program proceeded. ${ }^{5}$ He suggested that reduced standardization of reactor designs, partly to improve safety features, and especially the unsuccessful attempt to introduce a new design toward the end of the scale-up, was mainly responsible. The latter was motivated in part by a political desire to promote greater domestic value added for the nuclear industry and higher export market potential.

Green and Staffell [4] examine the issue of how Europe may reduce its use of fossil fuels. They use a dispatch model of the British wholesale electricity market and simulate how it is likely to evolve over time under different scenarios. They assume that power stations are added

\footnotetext{
${ }^{5}$ Nevertheless, the costs he provides for the French program are less than half the capital costs we use in our later calculations. The numbers that we use come from the United States Energy Information Administration (EIA).
} 
whenever they are expected to be profitable over their expected lifetimes, and are closed when they cannot cover their variable costs. This procedure means that the existing configuration of the system continues to influence its trajectory. A major message in the paper by Green and Staffell is that coal will be squeezed out of the system under policies that constrain $\mathrm{CO}_{2}$ emissions. Coal is also having difficulty competing against natural gas in the United States at the moment, given the currently low natural gas prices. In the analysis presented below, the only fossil fuel fired capacity that we consider is natural gas.

In a sense, we are interested in the opposite problem to the one discussed by Green and Staffell. We want to know how conclusions about what type of system may be desirable in the long run affect decisions about investments today and in the near future. An earlier paper [5] by Green and a different co-author, Vasilakos, is closer to what we do here. They use data on wind speeds (we have measured data on actual wind generator output in Texas) in the United Kingdom to simulate the effects of different levels of wind penetration on the long-run equilibrium of the system. They look at the residual load duration curve facing thermal generators after subtracting wind production (viewing wind generation as "negative demand") to calculate the likely effect of wind. In contrast to Green and Vasilakos, we are not just interested in the long-run effect of increasing wind penetration. Rather, our main focus is on wind and nuclear power as alternative non-fossil means of generating electricity in the long run. We also use linear programming to examine systems combining either of those technologies with natural gas plants. Our interest is not only in the costs and other characteristics of the different long-run systems, but also how those different systems might affect the type of investments that ought to be made in the intermediate and then short run.

There is also an extensive literature on electricity storage that is relevant to our paper. As we noted above, Trainer [15] emphasizes the necessity of bulk electricity storage in enabling renewable energy sources to continuously meet the load while maintaining network stability and power quality.

Experience coping with increasing wind generation in power networks also emphasizes the value of storage as a complement to wind. Green and Vasilakos [6] provide an interesting analysis of the case of Denmark, which has one of the highest levels of installed wind capacity relative to electricity demand. ${ }^{6}$ They emphasize the benefits of the connections between Denmark and countries to the north, where there is substantial hydroelectric capacity.

Green and Vasilakos use a simple model of a system with fixed quantities of wind and

\footnotetext{
${ }^{6} \mathrm{It}$ is a little misleading, however, to rank countries by the proportion of renewable capacity when the electricity network allows substantial trade in electricity. The ERCOT system that we analyze has only weak DC connections with its neighbors and operates substantially as a stand alone network.
} 
thermal capacity in one location (Denmark) and hydroelectricity in the other (Norway, Sweden and Finland), and with a connection of limited capacity between them. Their key conclusion is that, in the absence of transmission constraints or binding constraints - high or low - on reservoir storage, wind output should be accepted whenever it is available. Effectively, the resulting variations in water in storage represent a "battery" for the wind generation. Water should then be allocated across periods to equalize the thermal output, and hence thermal marginal cost, in each period. This equilibrated value also represents the shadow value of water. Green and Vasilakos also discuss the implications of the limited transmission capacity and other constraints, but the intuition of the unconstrained case informs their empirical analysis.

Green and Vasilakos find that short-term fluctuations in wind output in Denmark are highly correlated with short-term fluctuations in net exports of electricity to Norway, Sweden and Finland. The ability to trade power with neighbors possessing significant reservoirs for hydroelectricity generation thus allows Denmark to smooth daily or weekly fluctuations in wind output. At an annual timescale, however, Denmark's net exports of electricity are uncorrelated with wind production. Instead, there is a strong correlation between Denmark's annual net exports of electricity and its thermal production, and a negative correlation between those net exports and the level of hydro generation in Nordic countries. This, while Denmark uses water storage by its neighbors to offset short-term fluctuations in wind output, the neighbors use Denmark to cope with longer-term fluctuations in hydro power availability.

The importance of hydroelectricity as a means of smoothing out wind generation raises the question of how Texas can accommodate so much wind generation. ERCOT has almost 700MW of run-of-river hydroelectricity, but, like wind, its output is exogenous to demand or supply from other generators on the system. Instead, the more than $7 \mathrm{GW}$ of combustion turbine capacity explains how ERCOT can accommodate so much wind generation.

In contrast to wind generation, nuclear plants are generally operated to produce a very smooth flow of output. Since nuclear plants have high capital and low operating costs, it is generally efficient to operate them at full capacity except when being refueled. They are designed to operate that way in the United States, but in France and Germany nuclear plants have recently been operated in load following mode primarily to accommodate intermittent renewable generation (see Lokhov [11]). In the United States, it makes more sense to use natural gas-fired plants to accommodate load variation, especially given current natural gas prices.

Even though nuclear power plants are generally operated at full capacity, they also can benefit from electricity storage. Storage allows a higher capacity of nuclear power, since any excess of output over load can then be stored to be used when output is less than load. Trade 
in electricity can also substitute for storage in supporting nuclear power just as it does for wind. For example, one reason that France can accommodate so much nuclear capacity is that it can trade excess nuclear electricity generated at night to its neighbors.

There is also a substantial literature on electricity storage technologies. Luo et al. [12] provides a relatively recent overview of recent technological developments. They note that pumped hydroelectric storage represents more than $99 \%$ of current worldwide bulk storage capacity. It is the most mature technology, and is capable of storing large amounts of energy. Capacities of operating systems range up to more than $3 \mathrm{GW}$. The plants have $70-85 \%$ cycle efficiency and a lifetime of more than 40 years.

Rechargeable batteries of many sorts are also widely used, but not much for bulk electricity storage. Most facilities in operation have less than 10MW capacity. The limited lifespan, high self-discharge rate, and high maintenance costs of batteries make them too expensive.

Another technology currently in operation is compressed air storage. Cycle efficiencies are much lower than pumped storage - on the order of $50 \%$. Some variants that could have higher cycle efficiencies are under development. Some flywheel energy storage systems are also in operation. Cycle efficiencies up to $95 \%$ can be achieved in systems using non-contact magnetic bearings. The large inertia in these systems makes them particularly suitable for providing frequency control services, but they have modest storage capacity and store electricity for only short periods. Energy stored in the form of thermal energy is also used for load shifting. However, its cycle efficiency $(30-60 \%)$ is low.

Other technologies that Luo et al. discuss are more experimental. A promising technology that may be suitable for bulk electricity storage of up to several months is a flow battery system. These batteries use two separate liquid electrolyte tanks. The power of the system, which is determined by the size of the electrodes and the number of reaction cells, is independent of the storage capacity, which depends on the amount of electrolyte and its concentration. Since the electrolytes are stored separately, there is also little self-discharge.

The United States Department of Energy released a study on grid energy storage in 2013. They focus on the role that energy storage can play in enhancing renewable energy penetration into the network. Its role in smoothing the load on nuclear power plants is only mentioned in passing when discussing the development of energy storage in Japan. The report notes that the $23.4 \mathrm{GW}$ of pumped storage capacity in the United States represents about $95 \%$ of total storage capacity. The remainder is roughly one third each of thermal storage and compressed air, and one sixth each of batteries and flywheels. They identify four main barriers to more widespread deployment of energy storage: cost, validated performance and safety, unsupportive regulations 
and industry acceptance. In our analysis, we will take the cost of pumped storage as a realistic estimate of the cost of commercially viable bulk electricity storage systems.

The final study we shall mention, Cullen [2], used ERCOT data to examine the environmental benefits of wind generation. He begins by noting that subsidies paid to wind farms provided about half their revenue in $2010 .^{7}$ These subsidies are justified on the grounds that wind power entering the grid displaces fossil fuel generators, which in turn reduces emissions. The exact offset depends, however, on which type of generators are displaced when wind production increases.

Cullen uses 15-minute interval data from ERCOT from 2005-2007 to measure the output of each non-wind generator as a quadratic function of wind production. Noting that the diurnal and seasonal patterns for wind production may be correlated with incentives for production by other generators, he also includes as explanatory variables current and lagged values of aggregate load, temperature, and an indicator for when transmission lines are congested. To capture the effects of start-up and shut-down costs, he also includes the operating state for the generator two hours prior to production. The same lagged operating state variables for all the other generators on the grid are also included in each regression to allow for potential strategic interactions between generators. Each regression also includes a set of day by year indicator variables.

Before dynamics are accounted for, Cullen finds that each MWh of wind causes an average $0.85 \mathrm{MWh}$ reduction from gas generators, $0.18 \mathrm{MWh}$ reduction from coal generators and economically insignificant changes from other generators. After dynamic controls are introduced, coal offsets drop to almost zero while gas offsets increase to $0.92 \mathrm{MWh}$, of which $0.53 \mathrm{MWh}$ is from combined cycle, 0.32MWh from older steam plants and 0.07MWh from natural gas turbines. Since natural gas plants produce significantly less emissions than coal, the percentage reduction in emissions is substantially less than the proportion of electricity production represented by wind. Cullen's results are consistent with our conclusion below that introducing wind generation into an otherwise all natural gas system would primarily affect combined cycle plants.

\section{Data}

The main data set we use was prepared by ERCOT for its 2016 Wind Integration Report. This gives system load and wind output for every hour of the year. We used only the most recent year

\footnotetext{
${ }^{7}$ The source he cites is a study undertaken by the United States Department of Energy in 2007. This looks at direct expenditures by the Federal Government that ultimately result in direct payment to producers or consumers of energy; provisions in the Federal tax code that reduce the tax liability of firms or individuals who take specified actions affecting affect energy production, consumption, or conservation; Federal R\&D spending affecting energy production, transformation and end-use technologies; and electricity programs serving targeted categories of electricity consumers in several regions of the country. Many other programs, mandates, and exemptions from other policies not only at the Federal level but also at the State and Local Government levels support wind energy production. A summary of the hundreds of programs in operation can be found at http://www.dsireusa.org.
} 
because the amount of wind capacity is still growing and we wanted as much wind capacity as possible. Furthermore, until the almost $\$ 7$ billion Competitive Renewable Energy Zones (CREZ) transmission system upgrade was completed in 2014, transmission capacity was insufficient to get maximum output from wind farms in the west of the state to the main loads in the east, leading to frequent curtailment of wind output at night. Nevertheless, data going back to 2007 shows that the general relationship between wind output and system load has not changed noticeably over the decade.

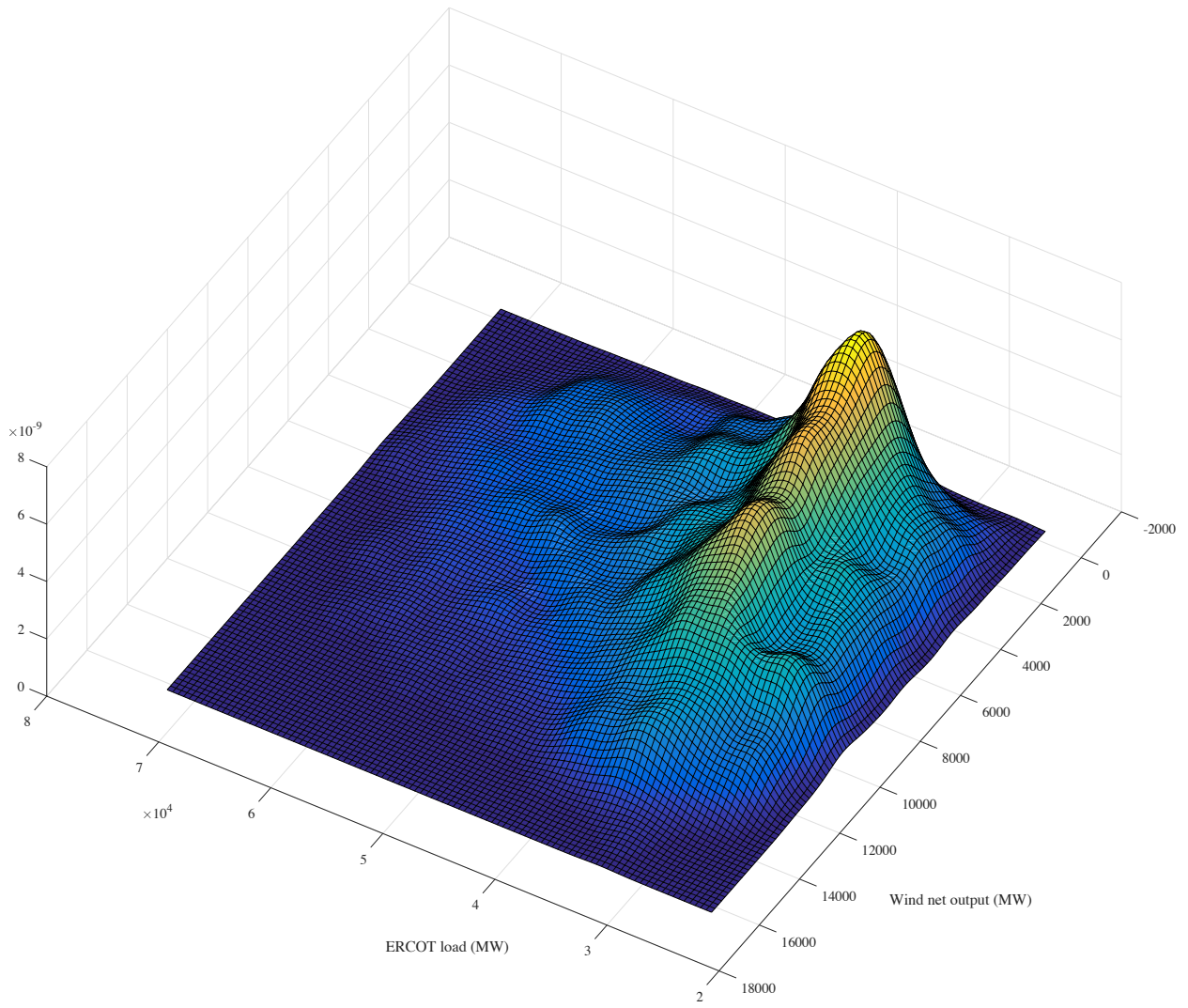

Figure 1: Bivariate density function for hourly ERCOT load and wind generation

Figure 1 graphs a kernel density estimate of the bivariate probability density function for hourly wind output and total ERCOT system load for 2016. ${ }^{8}$ Table 1 gives some summary statistics. Since wind capacity grew by more than $16 \%$ from $16.246 \mathrm{GW}$ at the beginning of 2016 to $18.923 \mathrm{GW}$ at the end, the table also provides statistics on the load factor for each hour. The mean load factor of more than $35 \%$ is quite high by international standards, especially given the inland location of almost all the wind farms.

In an ideal situation, wind output would be highest when system load is highest and vice versa. The "ridge" in Figure 1 would then run from the back right to the front left. In fact, there is a tendency for wind output to be lower when the ERCOT load is highest. The correlation

\footnotetext{
${ }^{8}$ The density was evaluated at 100 points in each dimension and a Gaussian kernel was used.
} 
between the two variables is -0.12 . In particular, wind output tends to be largest in late night and early morning hours when ERCOT load is relatively low. The variability of wind output is illustrated by the fact the while mean wind output is $15 \%$ of the mean ERCOT load, the standard deviation of wind output is more than $35 \%$ of the standard deviation of ERCOT load.

Table 1: Summary statistics

\begin{tabular}{lccc}
\hline \hline Statistic & ERCOT load (GW) & Wind output (GW) & Wind load factor (\%) \\
\hline min & 25.074 & 0.131 & 0.79 \\
max & 71.243 & 15.722 & 86.03 \\
mean & 40.0084 & 6.0742 & 35.46 \\
median & 37.633 & 5.746 & 33.66 \\
std. dev. & 9.4774 & 3.3867 & 19.87 \\
skewness & 0.941 & 0.286 & 0.275 \\
\hline
\end{tabular}

The second main data source we use is a 2016 report issued by the Energy Information Administration (EIA) on Capital Cost Estimates for Utility Scale Electricity Generating Plants. The cost estimates presented in the report were produced by an external consultant to the EIA using, where possible, data on actual or planned projects in the United States combined with generic assumptions for labor and materials costs. The cost estimates were developed using a common methodology across technologies. They represent the costs of a generic facility in a location that does not have unusual constraints or infrastructure requirements (including needed transmission upgrades). The EIA uses the estimates to develop energy projections and analyses, including forecasting retirements of old plants and the mix of generating capacity additions needed to serve future electricity demand.

We focused on six technologies. For fossil fuels, we examined only natural gas plants on the assumption that the lower emissions from natural gas combustion would make it a preferred technology in the longer-run time horizon that we are interested in. Specifically, we used the costs for "advanced natural gas combined cycle" (CC) and "advanced combustion turbine" (GT) technologies. For technologies that do not emit any $\mathrm{CO}_{2}$, we used onshore wind and "advanced nuclear". Since the 2016 report gives battery storage as the only electricity storage technology, we also used estimates of costs for pumped storage from the equivalent 2013 report. As we noted in the literature survey, pumped storage is currently the lowest cost electricity storage technology and the only one in extensive use.

The critical parameters are summarized in the top half of Table 2. The lower half of Table 2 contains parameters and calculations that do not come from the EIA publication referenced above. The fuel costs for the natural gas plants were developed by combining the heat rate for the plants specified in the EIA data with the average cost of natural gas delivered to power plants in the United States in 2016 (\$2.89/MMBTU), which was obtained from EIA natural 
gas statistics. The fuel cost for the nuclear plant was derived using the average monthly cost of $\mathrm{U}_{2} \mathrm{O}_{8}$ for 2016 ( $\$ 26.31 / \mathrm{lb}$, obtained from IMF statistics), an assumption of $180 \mathrm{MMBTU} / \mathrm{lb}$ of $\mathrm{U}_{2} \mathrm{O}_{8}$ and a heat rate for the plant of $10.452 \mathrm{MMBTU} / \mathrm{MWh}$. The resulting variable cost of $0.38 \mathrm{c} / \mathrm{kWh}$ closely approximates the reported cost of $0.4 \mathrm{c} / \mathrm{kWh}$ for the South Texas Project nuclear plant.

Table 2: Power plant capital and operating costs

\begin{tabular}{lcccccc}
\hline \hline Parameter & GT & CC & Wind & Nuclear & $\begin{array}{c}\text { Battery } \\
\text { storage }\end{array}$ & $\begin{array}{c}\text { Pumped } \\
\text { storage }\end{array}$ \\
\hline capital cost $(\$ \mathrm{~b} / \mathrm{GW})$ & 0.678 & 1.104 & 1.877 & 5.945 & 4.985 & 5.288 \\
size $(\mathrm{MW})$ & 237 & 429 & 100 & 2234 & 50 & 250 \\
fixed O\&M $(\$ \mathrm{~b} / \mathrm{GW})$ & 0.0068 & 0.01 & 0.0397 & 0.10028 & 0.1 & 0.018 \\
variable O\&M $(\$(000 / \mathrm{GWh})$ & 10.7 & 2.0 & 0 & 2.3 & 0 & 0 \\
\hline fuel $(\$ 1000 / \mathrm{GWh})$ & 28.35 & 18.22 & 0 & 1.53 & 0 & 0 \\
plant life & 30 & 30 & 25 & 60 & 15 & 50 \\
indicative load factor & 0.05 & 0.50 & 0.355 & 0.9008 & 0.12 & 0.12 \\
fixed/output $(\$ / \mathrm{kWh})$ & 14.66 & 2.36 & 6.69 & 7.00 & 63.24 & 40.48 \\
variable $(\Phi / \mathrm{kWh})$ & 3.90 & 2.02 & 0 & 0.38 & 0 & 0 \\
total LCOE $(\mathrm{\phi} / \mathrm{kWh})$ & 18.56 & 4.38 & 6.69 & 7.38 & 63.24 & 40.48 \\
\hline
\end{tabular}

For calculating the levelized cost of electricity (LCOE) in the lower half of Table 2, the life of the natural gas plants has been taken as 30 years. The National Electric Energy Data System (NEEDS) database v.5.13 shows that the average ages of GT and CC plants in operation in the United States as of 2015 were 26 years and 18 years respectively. Since many of the CC plants were still quite young and likely to be used for many more years, a lifetime of 30 years is likely to be conservative. The NEEDS database also gives retirement ages for the nuclear plants that imply they have a lifetime of 60 years. The average age of the pumped storage plants in the NEEDS database is 40 years, so we conservatively assumed a plant design life of 50 years. The wind turbines in the NEEDS database have been operating for an average of 10 years, but these are among the newest plants. Siemens Wind Power conducted life cycle assessments of wind turbines and suggested that their operating lifetimes are likely to approximate 25 years. With regard to battery technologies, Luo et al. [12] give ranges of only 5-15 years as a result of chemical deterioration with accumulated operating time. Since the cost of battery storage in Table 2 is so high, in the subsequent analysis, we will use the costs of pumped storage as an estimate of the costs that might eventually be obtained by other mass storage technologies.

The indicative load factors for natural gas entered in the table are relevant for the subsequent analysis. ${ }^{9}$ A Today in Energy fact sheet from the EIA published July 8, 2013 indicates that pumped storage in the United States currently operates at about a $12 \%$ load factor. The value

\footnotetext{
${ }^{9}$ Note that the LCOE is an average cost per unit of output and thus depends on the load factor of the plant. The calculation of fixed and variable costs from the assumptions is discussed further in the next section.
} 
for the wind load factor comes from the ERCOT data discussed above, while the load factor for nuclear plants is the realized average load factor for United States plants in recent years.

The final parameter used in the calculations is the interest rate, which should be the real aftertax weighted average cost of capital (WACC) for electric utilities. Public utility commissions in the United States allow regulated real equity returns of around 10\%. However, utilities often have leverage ratios of $40 \%$ with a real return on debt of around $6 \%$, suggesting a WACC around 7.5\%. The calculations in Table 2 use a WACC of $7.5 \%$, but in the analysis presented below we also look at the consequences of using $5 \%$ and $10 \%$ in addition to $7.5 \%$.

The relatively low LCOE for CC generators reflects the current low prices for natural gas in the United States. We would expect those prices to rise somewhat as more LNG is exported from the United States, linking prices there to prices in the rest of the world. In long run, prices worldwide will rise as natural gas resources are depleted. In the subsequent analysis we examine the effect of raising the natural gas price substantially above the 2016 average price.

While both wind and nuclear can generate power without emitting $\mathrm{CO}_{2}$, the LCOE calculations in the lower half of Table 2 suggest that wind should be preferable to nuclear for replacing fossil fuels. The analysis in the next section shows, however, that the LCOE calculations can be misleading when one has to ensure supply can always meet the load. The fact that wind output is very variable, not able to be dispatched as needed, and generally not well-correlated with system load can raise the cost of the overall system when there is a substantial amount of wind generation.

\section{Analysis and results}

We first use elementary methods to analyze the long-run systems with storage complementing nuclear or wind generation. Subsequently, we examine systems that can include natural gas, wind, nuclear and storage. This requires the use of linear programming.

\subsection{Long-run systems with storage and no fossil fuel}

We first consider the case where nuclear and storage are used. We imagine we have nuclear plants (running at $90.08 \%$ load factor) generating a constant flow of power. When output exceeds the load, the excess electricity is used to pump water into the upper reservoir of pumped storage facilities. Conversely, when the load exceeds the output of the nuclear plants, water is allowed to flow from the upper to the lower reservoir through turbines, which generate sufficient power to make up for the excess demand. The Today in Energy fact sheet from the EIA published July 8, 2013 referred to previously indicates that pumped storage in the United States currently 
operates at about $80 \%$ efficiency. In other words, only $80 \%$ of the electricity used to pump water up to the higher reservoir is produced when water is allowed to flow back down to the lower reservoir. We thus first calculated a "scaled average" nuclear power output by choosing a multiple $k$ of the average annual load $\bar{L}=\mathbb{E} L_{h}$ for 2016 (40.0084MW from Table 1$)$ such that:

$$
0.8 \sum_{\left\{h: L_{h}<k \bar{L}\right\}} k \bar{L}-L_{h}=\sum_{\left\{h: L_{h}>k \bar{L}\right\}} L_{h}-k \bar{L}
$$

The resulting solution for $k=1.021275$. In other words, to compensate for the electricity lost during storage the amount generated on a constant basis has to be about $2.1 \%$ above the average system load. To generate that amount using nuclear plants with an average load factor of 0.9008 , we would need $45.359 \mathrm{GW}$ of nuclear capacity.

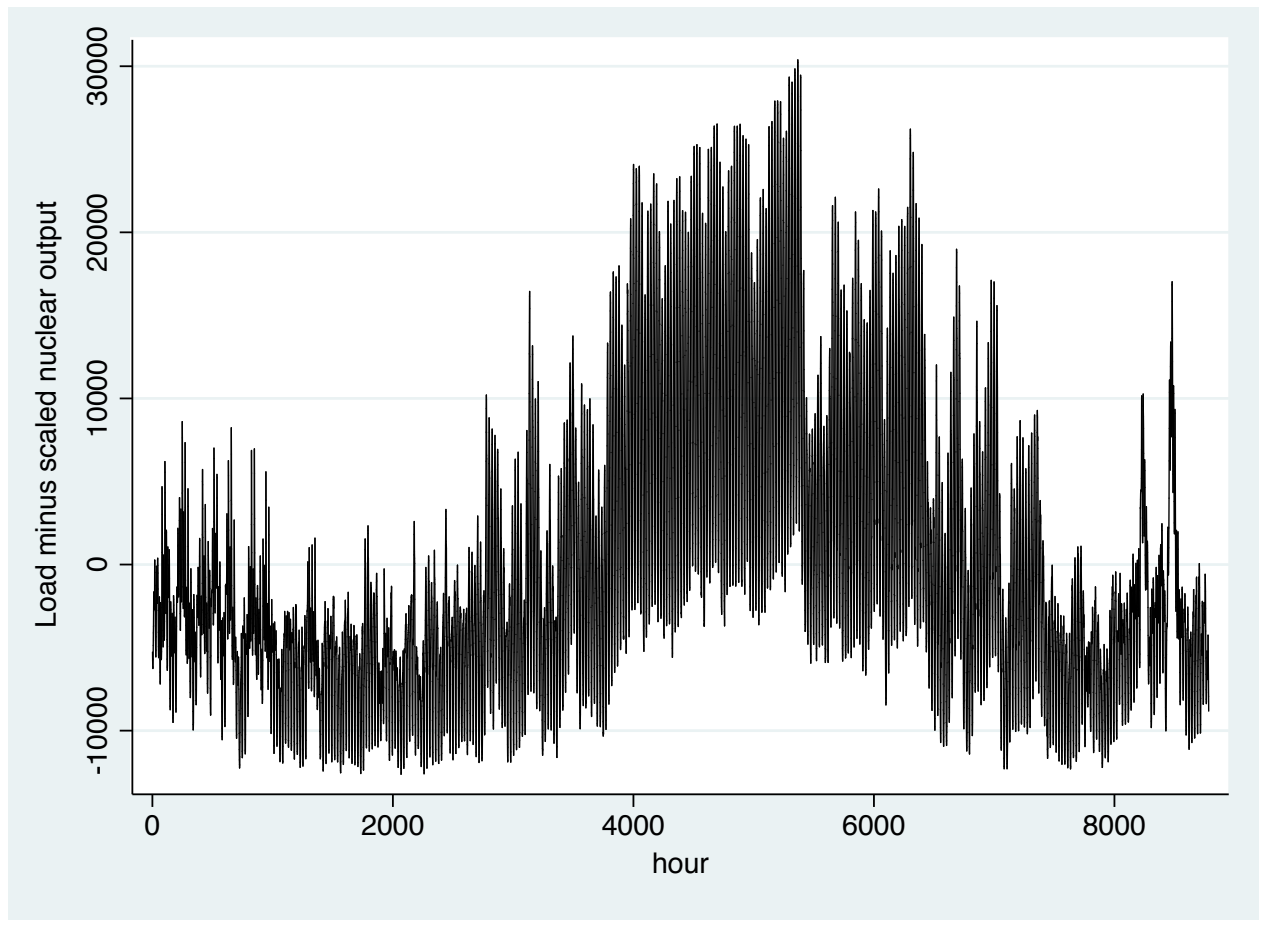

Figure 2: Deviations of load from nuclear output

Figure 2 graphs $0.8\left(L_{h}-k \bar{L}\right)$ if $L_{h}<k \bar{L}$ and $L_{h}-k \bar{L}$ if $L_{h}>k \bar{L}$ for each hour of 2016 . This corresponds to the amount of electricity stored or the amount produced from storage. The figure shows both daily and seasonal variations in load. Electricity demand in Texas peaks in the summer months when there is very high demand for air conditioning. The smaller increase in demand from December to February reflects increased use of electricity for heating.

The pumped storage generating capacity would be the maximum value graphed in Figure 2, which is $30.383 \mathrm{GW}$. Cumulating the amounts graphed in Figure 2, we find that the maximum 
stored energy would be equivalent to about 21.8 days of operation at full generating capacity. ${ }^{10}$ The average load factor of the pumped storage, measured by generated power divided by capacity times hours in a year would be $11.2 \%$, or slightly less than the load factor for pumped storage in the United States as reported above.

Finally, the system as configured would allow the exact distribution of load experienced in 2016 to be satisfied with an average capacity factor for the nuclear plants of $90.08 \%$. This allows for down-time for refueling and other problems. However, we add an additional $10 \%$ reserve plant margin to allow for stochastic variation in load and equipment failures, including transmission line outages. ${ }^{11}$ The lowest cost way of providing this capacity in a way that also would not involve much combustion of fossil fuels under normal operation is to add GT to the system. Given the maximum hourly load in 2016 of $71.243 \mathrm{GW}$, the annual capital cost of 7.124GW of GT (approximately the existing GT capacity in ERCOT) would be $\$ 457 \mathrm{~m}$.

We consider next a system with wind and storage. ${ }^{12}$ We need first to allow for the fact that the available wind capacity grew over 2016. We calculated the load factor for wind generation in every hour of 2016 and assumed that if the generating capacity had been the full amount available at the end of 2016, the load factor would have been the same as the actual one. Let the resulting wind generation in each hour be $W_{h}$. In order to calculate the amount of storage capacity, we again need to scale wind capacity and output by a factor $\omega$ such that $80 \%$ of the cumulative amount of excess generation over load equals ${ }^{13}$ the cumulative excess of load over generation over the year. Thus, (1) is modified to:

$$
0.8 \sum_{\left\{h: L_{h}<\omega W_{h}\right\}} \omega W_{h}-L_{h}=\sum_{\left\{h: L_{h}>\omega W_{h}\right\}} L_{h}-\omega W_{h}
$$

This process implicitly assumes that increasing wind generating capacity by a factor of $\omega$ will not change wind load factors or the patten of wind generation. In practice, the average quality of the sites, and thus wind load factors, are likely to decline as substantial amounts of wind

\footnotetext{
${ }^{10}$ Schoenung and Hassenzahl [14] provide a formula $V=400 E / h$ for the volume of water $V$ in $\mathrm{m}^{3}$ needed to store energy $E$ in $\mathrm{kWh}$ when the average head in $\mathrm{m}$ driving the turbine is $h$. If we take the average capacity of a storage facility to be $250 \mathrm{MW}$ as in Table 2, we would need around 122 facilities. If we assume the head is $300 \mathrm{~m}$, then the reservoirs would on average need to cover about $7 \mathrm{~km}^{2}-$ a circle of about $3 \mathrm{~km}$ diameter or a square $2.6 \mathrm{~km}$ on a side - to a depth of $25 \mathrm{~m}$.

${ }^{11}$ Costs of providing ancillary services will also include shut-down and start-up costs, but the EIA data does not provide any information about these.

${ }^{12}$ As Green and Staffell [4] observe, there can be problems maintaining network stability with wind turbines since they operate asynchronously and do not provide inertia to stabilize frequency. The actual system we will examine will also have natural gas turbines in addition to hydroelectric plants to help provide ancillary services.

${ }^{13}$ This procedure assumes that any excess of wind output over load is stored rather than "spilled." In the next section, we assume that the capacity to store energy is the same as the capacity to generate electricity from stored water. In the solution below, the maximum hourly storage rate is strictly less than the maximum hourly generation from storage. When the constraint on storing energy is never binding, one can show that it will not be optimal to spill generated wind power.
} 
generation are added. ${ }^{14}$ Nevertheless, proceeding with this assumption, we obtain a solution for $\omega=6.330453$. Given that the wind capacity in Texas was 18.923GW at the end of 2016, this means that we would require $119.791 \mathrm{GW}$ of wind capacity to generate power equal to the cumulated Texas load for 2016 after allowing for a $20 \%$ loss when using pumped storage. Once again we can visualize the electricity being stored and produced from pumped storage facilities by graphing $0.8\left(L_{h}-\omega W_{h}\right)$ if $L_{h}<\omega W_{h}$ and $L_{h}-\omega W_{h}$ if $L_{h}>\omega W_{h}$ for each hour of 2016, as in Figure 3.

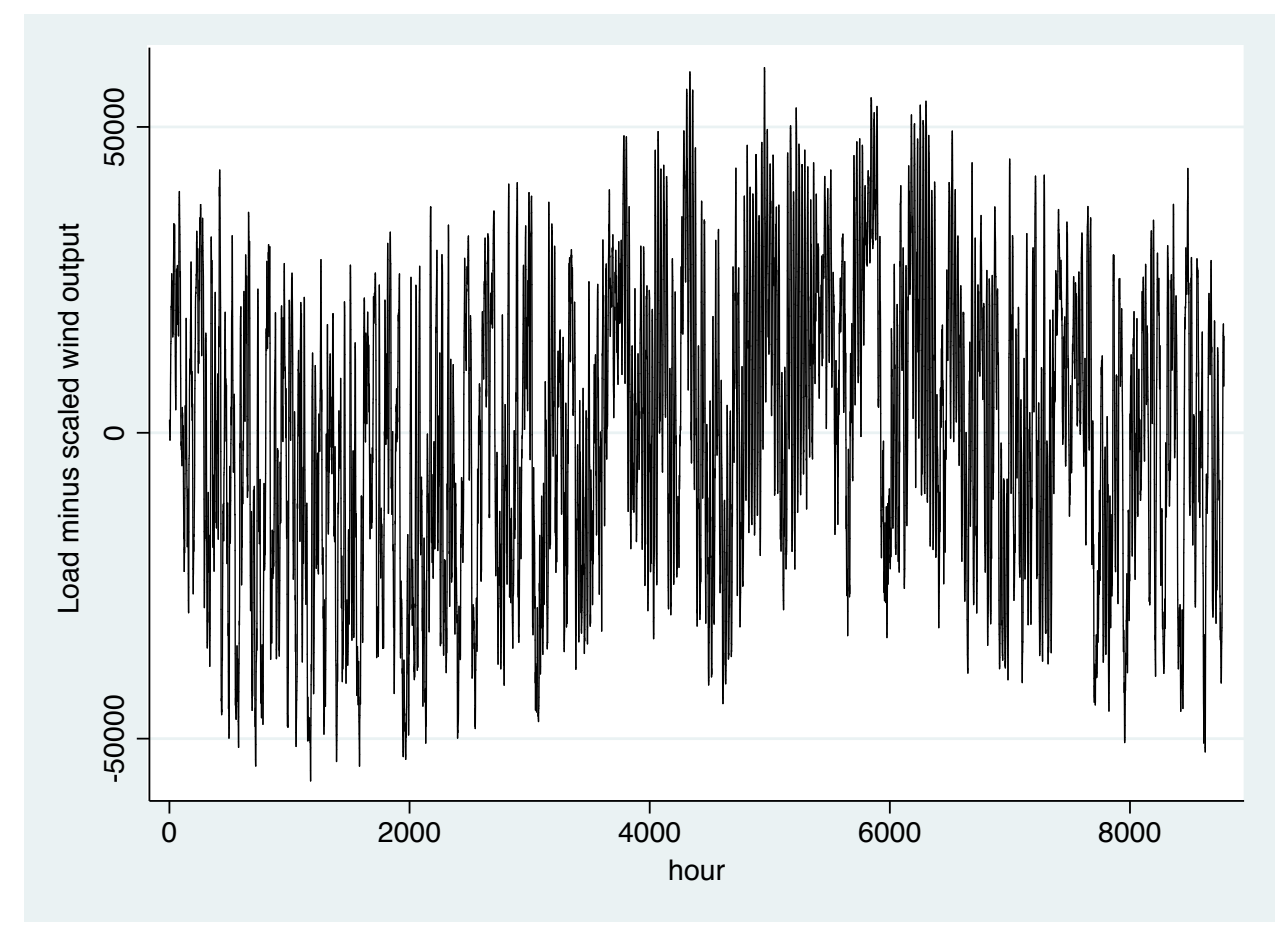

Figure 3: Deviations of load from wind output

The higher variance of the fluctuations in Figure 3 compared to Figure 2 reflects the high variability of wind output compared to system load. The mild negative correlation between wind output and load also means that the draw on storage in the summer can be much higher than under the nuclear scenario. In addition, the need to store excess generated power in the "low demand" spring and autumn seasons can be almost as large as the positive excess of load over generation in the summer. The tight daily cycle of demand evident in Figure 2 is also changed in Figure 3 into longer period cycles of excess supply or excess demand.

The pumped storage generating capacity is again the maximum value graphed in Figure 3, which in this case is $59.698 \mathrm{GW}$. This is more than $96 \%$ higher than in the nuclear case. The extreme variability of wind requires much more storage generating capacity. Cumulating the

\footnotetext{
${ }^{14}$ Although some of the best locations for generating wind power may not have been viable before the CREZ lines were built, it is likely by now that most of the best sites have been developed. An indication that the Texas sites developed to date have been high quality is that the 2016 average Texas load factor for wind farms of $35.46 \%$ is quite high by world standards.
} 
amounts graphed in Figure 3, the maximum storage volume needed in this case would be about 19.4 days of operation at maximum capacity. ${ }^{15}$ The average load factor of the pumped storage in this case would be $16.6 \%$. As with the nuclear case, we also allow for $7.124 \mathrm{GW}$ of GT for emergency backup capacity.

Recall that the LCOE in Table 2 were calculated using a real weighted average cost of capital of $7.5 \%$. Table 3 presents the results for this and two other discount rates. The average costs were calculated noting that the total electricity to be supplied is $351.433385 \mathrm{TWh}$.

Table 3: Solutions for costs in the long-run systems

\begin{tabular}{lccc}
\hline \hline & \multicolumn{3}{c}{ WACC } \\
& $\mathbf{0 . 0 5}$ & $\mathbf{0 . 0 7 5}$ & $\mathbf{0 . 1 0}$ \\
\hline Nuclear and storage & & & \\
Annual cost $(\$ \mathrm{~b})$ & 29.875 & 39.798 & 50.286 \\
Average cost $(\mathrm{\phi} / \mathrm{kWh})$ & 11.46 & 15.27 & 19.293 \\
Wind and storage & & & \\
Annual cost $(\$ \mathrm{~b})$ & 39.438 & 50.789 & 63.00 \\
Average cost $(\mathrm{\phi} / \mathrm{kWh})$ & 15.13 & 19.49 & 24.171 \\
\hline \hline
\end{tabular}

The cost of wind plus storage exceeds the cost of nuclear plus storage by more than $32 \%$ when $r=.05$ to around $25 \%$ when $r=0.10$. This is despite the result in Table 2 that the LCOE for wind is a little over $9.3 \%$ below the LCOE for nuclear. The reason is that variability of wind output requires almost double $(59.7 \mathrm{GW}$ versus $30.4 \mathrm{GW})$ the storage capacity, which is very expensive. Furthermore, while an increase in WACC favors wind over nuclear, a higher discount rate also raises the cost of storage. Hence, even at the unrealistically high (for a utility) real WACC of $10 \%$, the nuclear plus storage system is still less costly.

In practice, the difference in cost between the two systems is likely to exceed the values in Table 3 for several reasons. First, the calculations use the cost of pumped storage, which is currently by far the lowest cost method of bulk electricity storage. However, since a limited number of sites are suitable for pumped storage, more expensive solutions would also be needed. This will be more of a problem for the system with wind since it has almost double the required storage capacity. Second, as more pumped storage sites are exploited, sites that are more expensive to develop, or which are more remote and therefore require additional transmission lines to be built, are likely to be needed. Third, the wind resource itself is often distant from markets and requires additional transmission lines to be built. For example, Texas electricity consumers had to finance an almost $\$ 7$ billion expansion in high voltage transmission lines (in

\footnotetext{
${ }^{15}$ The maximum storage volume may be larger for nuclear because of the stronger seasonality in the flows in to an out of storage. Repeating the calculations of storage volume, in this case we would need around 239 facilities of $250 \mathrm{MW}$ capacity. Using the same head of $300 \mathrm{~m}$ and depth of $25 \mathrm{~m}$, the surface area of each reservoir would now need to be about $6.2 \mathrm{~km}^{2}$. Natural runoff into the upper reservoir and evaporation from it can also affect the energy efficiency of pumped storage. Evaporative loss may be a particular problem in the Texas summer.
} 
the CREZ project) to facilitate the exploitation of an additional $12 \mathrm{GW}$ of wind resources in west Texas. These lines, like the wind generation capacity itself, are used at a low load factor and thus are expensive per unit of energy delivered. By contrast, nuclear plants can be built much closer to the main load centers and any new transmission lines required are likely to be much shorter and used at much higher load factors.

The result that the wind plus storage system has a higher cost than the nuclear plus storage one has an important implication. As noted in the introduction, it is often argued that storage would solve the problems with wind generation - its intermittency, non-dispatchability, and generally negative correlation with system load. Our result implies, however, that far from making highly variable and uncontrollable sources of generation more competitive, storage would in fact better advantage stable and controllable generation. With storage, such sources can be used to continuously to reliably supply the average load at low cost.

The amount of electricity storage required under these two scenarios is extraordinary. It is about $30 \%$ more than the current pumped storage capacity in all of the United States in the nuclear case, and more than 2.5 times current United States capacity in the wind case. As we will see in the next sub-section, the need for so much storage will delay the transition to the long-run system.

\subsection{Including natural gas generation}

Allowing for any combination of natural gas, wind, nuclear and storage results in a more complicated problem that can only be solved using linear programing. The linear program takes as inputs the vectors of hourly wind outputs (scaled to end of year wind generating capacity) $W_{h}$ and system loads $L_{h}$ in ERCOT in 2016. The choice variables include a scale multiple $\omega$ of the wind capacity $(18.923 \mathrm{GW})$ and outputs. The capacities $K_{C}$ of CC, $K_{T}$ of GT and $K_{N}$ of nuclear, and the outputs $G C_{h} \leq K_{C}, G T_{h} \leq K_{T}, N_{h} \leq K_{N}$ from these plants in each hour, also need to be chosen. Finally, the pumping and generating capacity for pumped storage, and the electricity used for pumping or the electricity generated from the stored water in every hour, also need to be chosen. For simplicity, we assume that these facilities use reversible equipment that can be operated as either a pump motor or a turbine generator. However, due to electrical and hydraulic losses, the amount generated is only $80 \%$ of the amount of electricity consumed for pumping. We let $K_{P}$ be the total generating capacity of the pumped storage facilities and $P U_{h} \leq K_{P} / 0.8$ the electricity used in pumping and $P D_{h} \leq K_{P}$ the electricity generated from storage for each hour of the year. 
The objective to be minimized is annual system costs:

$$
F_{C} K_{C}+F_{T} K_{T}+18.923 \omega F_{W}+F_{P} K_{P}+F_{N} K_{N}+\sum_{h} V_{C} G C_{h}+\sum_{h} V_{T} G T_{h}+\sum_{h} V_{N} N_{h}
$$

where $F_{i}, i \in\{C, T, W, P, N\}$ are the equivalent annual fixed costs per GW of capacity of each type of plant and $V_{i}, i \in\{C, T, N\}$ are variable costs for natural gas and nuclear plants. Denote the capital costs (Table 2 row 1 ) in $\$ \mathrm{~b} / \mathrm{GW}$ of capacity for a plant of type $i$ by $p_{i}$ and the fixed O\&M costs (Table 2 row 3 ) in $\$ \mathrm{~b} / \mathrm{GW}$ by $q_{i}$. Also let $A_{r}^{N_{i}}$, for plant lifetime $N_{i}$ and discount rate $r$, be the annuity factor required to convert the capital costs of $p_{i}$ to equivalent annual costs. The fixed costs per unit of capacity, measured in $\$ b / G W$, can then be written as

$$
F_{i}=q_{i}+\frac{p_{i}}{A_{r}^{N_{i}}}
$$

Letting $v_{i}, i \in\{C, T, N\}$ denote the variable O\&M costs (Table 2 row 4), and $f_{i}, i \in\{C, T, N\}$ the fuel costs, of the thermal plants in thousands of dollars, the variable costs in $\$ \mathrm{~b} / \mathrm{GWh}$ are

$$
V_{i}=\left(v_{i}+f_{i}\right) \times 10^{-6}
$$

The minimization is subject to a set of demand and storage constraints for each hour that generalize (1) and (2). In particular, we allow generation to exceed load since it could be optimal to have $K_{P}$ small and $\omega$ large with wind generation "spilled":

$$
\begin{gathered}
G C_{h}+G T_{h}+\omega W_{h}+N_{h}+P D_{h} \geq L_{h}+P U_{h} \\
0.8 \sum_{h} P U_{h}=\sum_{h} P D_{h}
\end{gathered}
$$

The reserve plant margin constraint requires primarily dispatchable (natural gas, nuclear and pumped storage) capacity to exceed the maximum hourly load for the year by $10 \%$. However, we also allow for a capacity contribution from wind. Specifically, we allowed the minimum wind generation in the $5 \%$ of the hours in 2016 with the highest hourly loads, namely $2.717 \mathrm{GW}$, to scale with $\omega$ in contributing to the reserve plant margin constraint:

$$
K_{C}+K_{T}+2.717 \omega+K_{P}+K_{N} \geq 1.1 \max _{h} L_{h}
$$

Finally, we calculate the total amount of natural gas used over the year (in quads or $10^{15}$ BTU):

$$
E=\sum_{h} H_{C} G C_{h}+\sum_{h} H_{T} G T_{h}
$$


where $H_{C}=6.3 \times 10^{-6}$ quads/GWh and $H_{T}=9.8 \times 10^{-6}$ quads/GWh are the heat rates of the $\mathrm{CC}$ and GT plants from the EIA data discussed previously. Initially, we will assume that $E$ is unconstrained and we examine the solutions as WACC and $p_{N G}$ vary. Subsequently, we will also examine the effect of quantitative restrictions on the total amount of natural gas used.

Figure 4 graphs an example hourly solution for generation with substantial output from all generator types. ${ }^{16}$ Note the changes in scale on the vertical axes of the various sub-graphs. Apart from the peak summer season, variability of load (top sub-graph) minus wind output (second sub-graph) is reflected mainly in CC output variability (third sub-graph). During the peak season, CC plants are run at full capacity during the day, but cycled below capacity at night to accommodate increased wind production. During daylight hours in the peak season, GT (fourth sub-graph) compensate for variation in load and wind output. Nuclear output (final sub-graph) is virtually the same in every hour. The only exceptions occur for some hours in the spring when very high wind output coinciding with a low load results in some curtailment of nuclear output. Even modest costs of cycling nuclear capacity (which are ignored in this analysis) would likely make it preferable to spill the excess wind output in those periods.

Table 4 presents solutions for a range of natural gas prices (measured relative to the average cost of natural gas delivered to power plants in the United States in 2016) and the same WACC values as in Table 3. The all natural gas system has the lowest cost even as the natural gas price rises substantially. This reflects the fuel-efficiency of natural gas generation and the ability to operate CC at high load factors. Nevertheless, higher natural gas prices increase CC and especially GT costs. Reduced GT capacity requires CC to be used in higher demand periods, reducing its load factor and further raising its cost. Eventually, the wind or nuclear plants become competitive. Consistent with the results of Cullen [2] discussed previously, when wind or nuclear are introduced into the system, they displace CC plants more than GT.

The relatively low capital intensity of natural gas generation increases its advantage as the discount rate rises. At a $5 \%$ WACC, the natural gas price has to rise by around $140 \%$ before nuclear generation can compete. At 7.5\% WACC, the gas price has to rise about $215 \%$, and at $10 \%$ WACC by about $290 \%$, before alternative generation becomes competitive.

At a WACC of $7.5 \%$ or $10 \%$, wind generation displaces natural gas as the natural gas price increases. At a $5 \%$ WACC, however, the transition is from natural gas to nuclear even though the LCOE of nuclear exceeds the LCOE of wind generation. This again shows that the LCOE is not a reliable guide to the overall cost of including a generation technology in the system.

\footnotetext{
${ }^{16}$ Only the CC, GT or nuclear generators are marginal, however, and the multiplier $\lambda_{h}$ on the demand constraint in hour $h$ in (6) equals the corresponding LCOE for the capacity that is marginal in hour $h$. If we let the multiplier on the reserve capacity constraint (7) be $\mu$ then $\sum_{h} \lambda_{h} L_{h}+1.1 \mu \max _{h} L_{h}$ equals the minimized system cost.
} 
Editor, UWA Economics Discussion Papers:

Sam Hak Kan Tang

University of Western Australia

35 Sterling Hwy

Crawley WA 6009

Australia

Email: ecoadmin@biz.uwa.edu.au

The Economics Discussion Papers are available at:

1980 - 2002: http://ecompapers.biz.uwa.edu.au/paper/PDF\%20of\%20Discussion\%20Papers/

Since 2001: $\quad$ http://ideas.repec.org/s/uwa/wpaper1.html

Since 2004: $\quad$ http://www.business.uwa.edu.au/school/disciplines/economics

\begin{tabular}{|c|c|c|}
\hline \multicolumn{3}{|c|}{ ECONOMICS DISCUSSION PAPERS - 2016} \\
\hline $\begin{array}{l}\text { DP } \\
\text { NUMBER }\end{array}$ & AUTHORS & TITLE \\
\hline 16.01 & $\mathrm{Xu}, \mathrm{R} ., \mathrm{Wu}, \mathrm{Y}$. and Luan, J. & $\begin{array}{l}\text { ANALYSIS OF FARMERS' WILLINGNESS TO ADOPT } \\
\text { GENETICALLY MODIFIED INSECT-RESISTANT RICE IN } \\
\text { CHINA }\end{array}$ \\
\hline 16.02 & $\begin{array}{l}\text { Lia, Y., Fan, J., Zhao, D., Wu, Y. and } \\
\text { Li, J. }\end{array}$ & $\begin{array}{l}\text { TIERED GASOLINE PRICING: A PERSONAL CARBON } \\
\text { TRADING PERSPECTIVE }\end{array}$ \\
\hline 16.03 & Clements, K.W., Lan, Y. and Si, J. & UNCERTAINTY IN CURRENCY MISPRICING \\
\hline 16.04 & Parsons, C. and Vézina, P.L. & $\begin{array}{l}\text { MIGRANT NETWORKS AND TRADE:THE VIETNAMESE } \\
\text { BOAT PEOPLE AS A NATURAL EXPERIMENT }\end{array}$ \\
\hline 16.05 & Chang, S., Connelly, R. and Ma, P. & $\begin{array}{l}\text { WHAT WILL YOU DO IF I SAY ‘I DO’?: THE EFFECT OF } \\
\text { THE SEX RATIO ON TIME USE WITHIN TAIWANESE } \\
\text { MARRIED COUPLES }\end{array}$ \\
\hline 16.06 & $\mathrm{Yu}, \mathrm{F}$. and $\mathrm{Wu}, \mathrm{Y}$. & $\begin{array}{l}\text { BIASES IN PATENT EXAMINATION AND FIRMS' } \\
\text { RESPONSES: EVIDENCE FROM THE } \\
\text { PHARMACEUTICAL INDUSTRY }\end{array}$ \\
\hline 16.07 & $\begin{array}{l}\text { Fan, J., Li, J., Wu, Y., Wang, S. and } \\
\text { Zhao, D. }\end{array}$ & $\begin{array}{l}\text { THE EFFECTS OF ALLOWANCE PRICE ON ENERGY } \\
\text { DEMAND UNDER A PERSONAL CARBON TRADING } \\
\text { SCHEME }\end{array}$ \\
\hline 16.08 & Golley, J., Tyers, R. and Zhou, Y. & $\begin{array}{l}\text { CONTRACTIONS IN CHINESE FERTILITY AND } \\
\text { SAVINGS: LONG RUN DOMESTIC AND GLOBAL } \\
\text { IMPLICATIONS }\end{array}$ \\
\hline 16.09 & McGrath, G. and Neill, K. & $\begin{array}{l}\text { FOREIGN AND DOMESTIC OWNERSHIP IN WESTERN } \\
\text { AUSTRALIA'S GAS MARKET }\end{array}$ \\
\hline 16.10 & Clements, K.W. and Si, J. & SIMPLIFYING THE BIG MAC INDEX \\
\hline 16.11 & Priyati, R.Y. and Tyers, R. & $\begin{array}{l}\text { PRICE RELATIONSHIPS IN VEGETABLE OIL AND } \\
\text { ENERGY MARKETS }\end{array}$ \\
\hline 16.12 & Wu, J., Wu, Y. and Wang, B. & $\begin{array}{l}\text { THE GREENNESS OF CHINESE CITIES: CARBON } \\
\text { DIOXIDE EMISSION AND ITS DETERMINANTS }\end{array}$ \\
\hline 16.13 & $\begin{array}{l}\text { Arslan, C., Dumont, J.C., Kone, Z., } \\
\text { Özden, Ç., Parsons, C. and } \\
\text { Xenogiani, T. }\end{array}$ & $\begin{array}{l}\text { INTERNATIONAL MIGRATION TO THE OECD IN THE } \\
\text { TWENTY-FIRST CENTURY }\end{array}$ \\
\hline 16.14 & Tomioka, K. and Tyers, R. & $\begin{array}{l}\text { HAS FOREIGN GROWTH CONTRIBUTED TO } \\
\text { STAGNATION AND INEQUALITY IN JAPAN? }\end{array}$ \\
\hline 16.15 & Donovan, J. and Hartley, P. & $\begin{array}{l}\text { RIDING THE IRON ORE CYCLE: ACTIONS OF } \\
\text { AUSTRALIA'S MAJOR PRODUCERS }\end{array}$ \\
\hline 16.16 & Czaika, M. and Parsons, C. & $\begin{array}{l}\text { HIGH-SKILLED MIGRATION IN TIMES OF GLOBAL } \\
\text { ECONOMIC CRISIS }\end{array}$ \\
\hline
\end{tabular}




\begin{tabular}{|l|l|l|}
\hline 16.17 & Lefroy, T., Key, J. and Kingwell, R. & $\begin{array}{l}\text { A LONGITUDINAL EXAMINATION OF BROADACRE } \\
\text { FARM SIZE AND PERFORMANCE IN WESTERN } \\
\text { AUSTRALIA }\end{array}$ \\
\hline 16.18 & Arthmar, R. and McLure, M. & $\begin{array}{l}\text { SRAFFA, MYRDAL AND THE 1961 SÖDERSTRÖM GOLD } \\
\text { MEDAL }\end{array}$ \\
\hline 19.19 & Azwar, P. and Tyers, R. & $\begin{array}{l}\text { POST-GFC EXTERNAL SHOCKS AND INDONESIAN } \\
\text { ECONOMIC PERFORMANCE }\end{array}$ \\
\hline 19.20 & Chen, A. and Groenewold, N. & $\begin{array}{l}\text { OUTPUT SHOCKS IN CHINA: DO THE DISTRIBUTIONAL } \\
\text { EFFECTS DEPEND ON THE REGIONAL SOURCE? }\end{array}$ \\
\hline 19.21 & Wu, Y., Zhu, X. and Groenewold, N. & $\begin{array}{l}\text { THE DETERMINANTS AND EFFECTIVENESS OF } \\
\text { INDUSTRIAL POLICY IN CHINA: A STUDY BASED ON } \\
\text { FIVE-YEAR PLANS }\end{array}$ \\
\hline 16.22 & Liu, H. & $\begin{array}{l}\text { THE INCOME AND PRICE SENSITIVITY OF DIETS } \\
\text { GLOBALLY }\end{array}$ \\
\hline 16.23 & Asano, A., Neill, K. and Yamazaki, S. & $\begin{array}{l}\text { DECOMPOSING FISHING EFFORT: MODELLING THE } \\
\text { SOURCES OF INEFFICIENCY IN A LIMITED-ENTRY } \\
\text { FISHERY }\end{array}$ \\
\hline 16.24 & Golley, J., Tyers, R. and Zhou, Y. & $\begin{array}{l}\text { FERTILITY AND SAVINGS CONTRACTIONS IN CHINA: } \\
\text { LONG-RUN GLOBAL IMPLICATIONS }\end{array}$ \\
\hline 16.25 & Taylor, G., Tyers, R. & $\begin{array}{l}\text { Secular Stagnation: Determinants and Consequences for } \\
\text { Australia }\end{array}$ \\
\hline
\end{tabular}

\begin{tabular}{|l|l|l|}
\hline \multicolumn{2}{|c|}{ ECONOMICS DISCUSSION PAPERS - 2017 } \\
\hline $\begin{array}{c}|c| \\
\text { DP } \\
\text { NUMBER }\end{array}$ & \multicolumn{1}{|c|}{ AUTHORS } & \multicolumn{1}{c|}{ TITLE } \\
\hline 17.01 & Tyers, R. and Zhou, Y. & $\begin{array}{l}\text { AUTOMATION AND INEQUALITY WITH TAXES AND } \\
\text { TRANSFERS }\end{array}$ \\
\hline 17.02 & Ye, L. and Robertson, P. & $\begin{array}{l}\text { HITTING THE GREAT WALL: RURAL-URBAN } \\
\text { MIGRATION AND CHINA'S GROWTH SLOWDOWN }\end{array}$ \\
\hline 17.03 & Ye, L. and Robertson, P. & $\begin{array}{l}\text { MIGRATION AND GROWTH IN CHINA: A SCEPTICAL } \\
\text { ASSESSMENT OF THE EVIDENCE }\end{array}$ \\
\hline 17.04 & Clements, K. Si, J. and Vo, L. & $\begin{array}{l}\text { FOOD AND AGRICULTURAL PRICES ACROSS } \\
\text { COUNTRIES AND THE LAW OF ONE PRICE }\end{array}$ \\
\hline 17.05 & $\begin{array}{l}\text { Chen, M., Clements, K., Gao, G. and } \\
\text { Si, J. }\end{array}$ & $\begin{array}{l}\text { THREE FACTS ABOUT WORLD METAL PRICES } \\
\text { Cornes, R., Fiorini, L. and }\end{array}$ \\
\hline 17.06 & Maldonado, W. & $\begin{array}{l}\text { EXPECTATIONAL STABILITY IN AGGREGATIVE } \\
\text { GAMES }\end{array}$ \\
\hline 17.07 & $\begin{array}{l}\text { THE COST OF DISPLACING FOSSIL FUELS: SOME } \\
\text { EVIDENCE FROM TEXAS }\end{array}$ \\
\hline 17.08 & Shehabi, M. R. & $\begin{array}{l}\text { GSSESSING KUWAITI ENERGY PRICINING REFORMS } \\
\text { INTERACTION OR UNILATERAL GAINS? }\end{array}$ \\
\hline 17.09 & Perdana, S. and Tyers, R. & \\
\hline
\end{tabular}



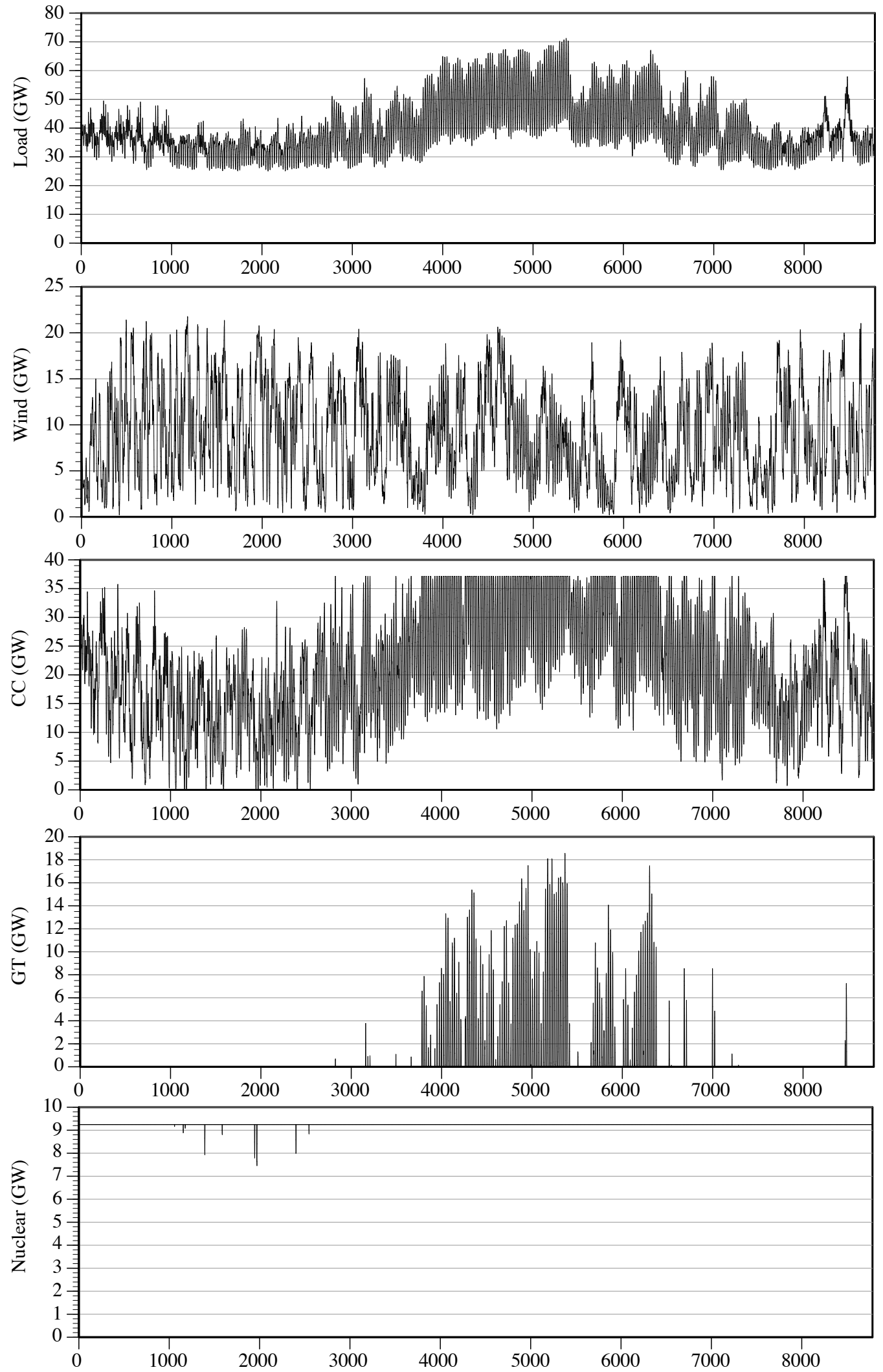

Figure 4: Hourly outputs and load when $r=0.075, p_{N G}=9.40$ 
Table 4: LP solutions for different interest rates and natural gas prices

\begin{tabular}{|c|c|c|c|c|c|c|c|}
\hline \multirow[b]{2}{*}{ Variable } & \multicolumn{7}{|c|}{ Natural gas price relative to 2016 (\$2.89/MMBTU) } \\
\hline & 1.0 & 2.0 & 2.5 & 3.0 & 3.5 & 4.0 & 4.5 \\
\hline \multicolumn{8}{|l|}{$r=.05$} \\
\hline Annual cost (\$b) & 12.835 & 19.337 & 22.265 & 23.112 & 23.707 & 24.182 & 24.484 \\
\hline Average cost $(\Phi / \mathrm{kWh})$ & 3.65 & 5.50 & 6.34 & 6.58 & 6.75 & 6.88 & 6.97 \\
\hline CC capacity (GW) & 48.078 & 53.042 & 27.720 & 23.575 & 22.355 & 17.963 & 17.503 \\
\hline GT capacity (GW) & 30.289 & 25.325 & 20.753 & 18.804 & 17.548 & 16.458 & 15.834 \\
\hline Wind capacity (GW) & 0 & 0 & 0 & 0 & 0 & 0 & 0 \\
\hline Nuclear capacity (GW) & 0 & 0 & 29.895 & 35.988 & 38.465 & 40.020 & 42.197 \\
\hline Pumped storage capacity (GW) & 0 & 0 & 0 & 0 & 0 & 1.926 & 2.833 \\
\hline CC load factor $(\%)$ & 80.05 & 73.97 & 45.13 & 32.87 & 27.55 & 19.45 & 17.89 \\
\hline GT load factor (\%) & 5.03 & 3.05 & 2.84 & 2.45 & 2.14 & 1.94 & 1.76 \\
\hline Nuclear load factor (\%) & & & 90.01 & 88.36 & 87.03 & 86.64 & 87.43 \\
\hline Storage load factor (\%) & & & & & & 44.04 & 41.44 \\
\hline Fuel used $\left(10^{15} \mathrm{BTU}\right)$ & 2.261 & 2.238 & 0.743 & 0.468 & 0.373 & 0.221 & 0.197 \\
\hline \multicolumn{8}{|l|}{$r=.075$} \\
\hline Annual cost (\$b) & 14.267 & 20.811 & 24.058 & 27.295 & 29.385 & 30.183 & 30.797 \\
\hline Average cost $(\Phi / \mathrm{kWh})$ & 4.06 & 5.92 & 6.85 & 7.77 & 8.36 & 8.59 & 8.76 \\
\hline CC capacity (GW) & 45.289 & 50.175 & 52.146 & 53.727 & 26.436 & 23.576 & 22.375 \\
\hline GT capacity (GW) & 33.078 & 28.192 & 26.221 & 24.640 & 20.750 & 18.903 & 17.985 \\
\hline Wind capacity (GW) & 0 & 0 & 0 & 0 & 1.806 & 0 & 0 \\
\hline Nuclear capacity $(\mathrm{GW})$ & 0 & 0 & 0 & 0 & 30.922 & 35.888 & 38.007 \\
\hline Pumped storage capacity (GW) & 0 & 0 & 0 & 0 & 0 & 0 & 0 \\
\hline CC load factor $(\%)$ & 83.67 & 77.41 & 75.03 & 73.18 & 41.82 & 33.14 & 28.67 \\
\hline GT load factor $(\%)$ & 6.39 & 4.14 & 3.37 & 2.80 & 2.74 & 2.48 & 2.26 \\
\hline Nuclear load factor (\%) & & & & & 89.72 & 88.41 & 87.32 \\
\hline \multicolumn{8}{|l|}{ Storage load factor (\%) } \\
\hline Fuel used $\left(10^{15} \mathrm{BTU}\right)$ & 2.279 & 2.250 & 2.241 & 2.235 & 0.661 & 0.473 & 0.390 \\
\hline \multicolumn{8}{|l|}{$r=.10$} \\
\hline Annual cost (\$b) & 15.806 & 22.395 & 25.659 & 28.911 & 32.154 & 34.964 & 36.669 \\
\hline Average cost $(\Phi / k W h)$ & 4.50 & 6.37 & 7.30 & 8.23 & 9.15 & 9.95 & 10.43 \\
\hline CC capacity $(\mathrm{GW})$ & 42.930 & 47.914 & 49.686 & 51.280 & 52.715 & 41.770 & 27.931 \\
\hline GT capacity (GW) & 35.437 & 30.453 & 28.681 & 27.087 & 25.652 & 30.495 & 24.129 \\
\hline Wind capacity (GW) & 0 & 0 & 0 & 0 & 0 & 42.499 & 17.398 \\
\hline Nuclear capacity $(\mathrm{GW})$ & 0 & 0 & 0 & 0 & 0 & 0 & 23.810 \\
\hline Pumped storage capacity (GW) & 0 & 0 & 0 & 0 & 0 & 0 & 0 \\
\hline CC load factor $(\%)$ & 86.82 & 80.26 & 78.02 & 76.06 & 74.36 & 57.85 & 43.08 \\
\hline GT load factor $(\%)$ & 7.72 & 5.10 & 4.34 & 3.70 & 3.16 & 2.25 & 2.55 \\
\hline Nuclear load factor (\%) & & & & & & & 88.99 \\
\hline \multicolumn{8}{|l|}{ Storage load factor (\%) } \\
\hline Fuel used $\left(10^{15} \mathrm{BTU}\right)$ & 2.298 & 2.262 & 2.252 & 2.245 & 2.239 & 1.407 & 0.719 \\
\hline
\end{tabular}




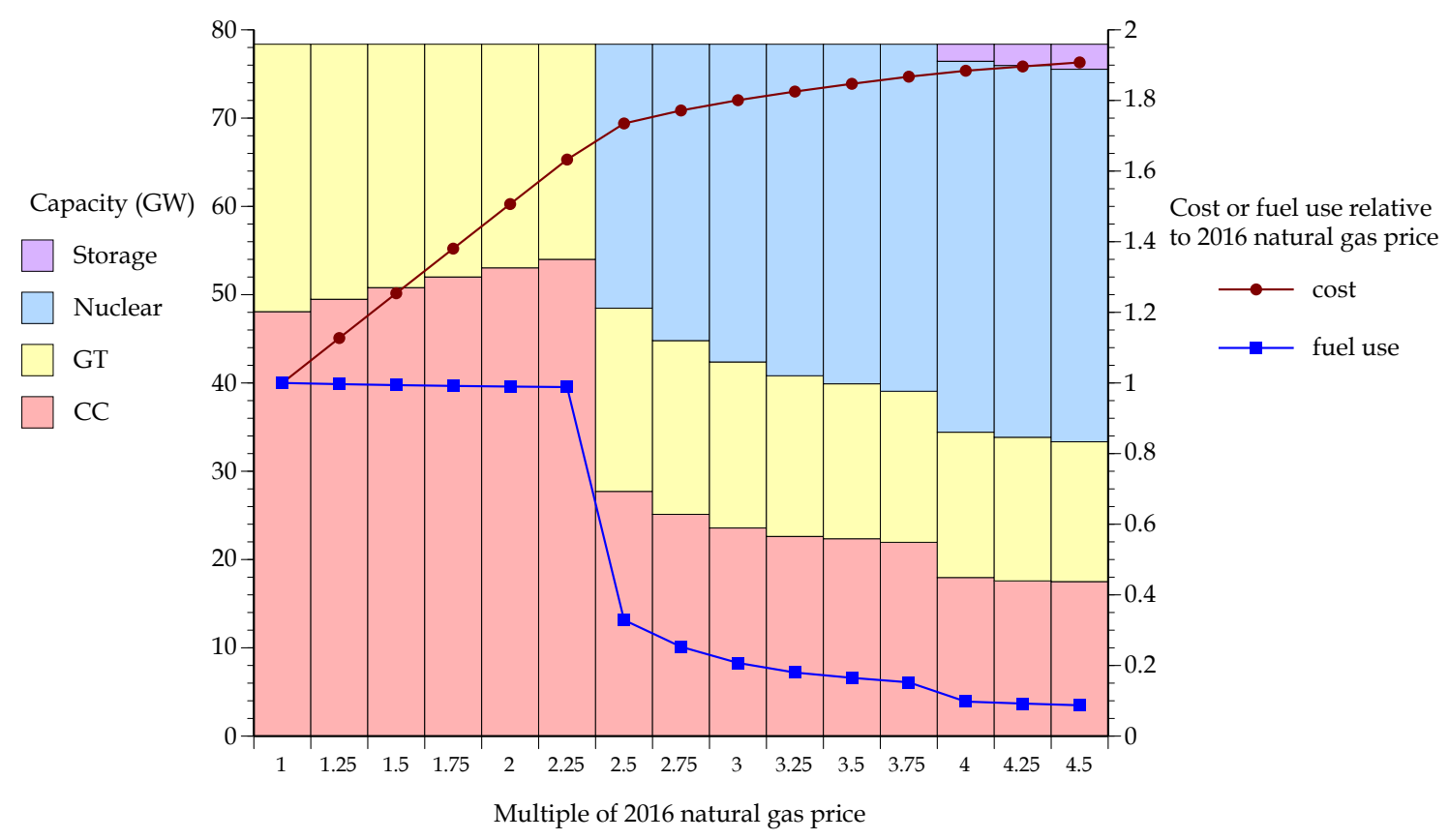

Figure 5: Optimal capacity mix, minimized cost and fuel use when $r=0.05$

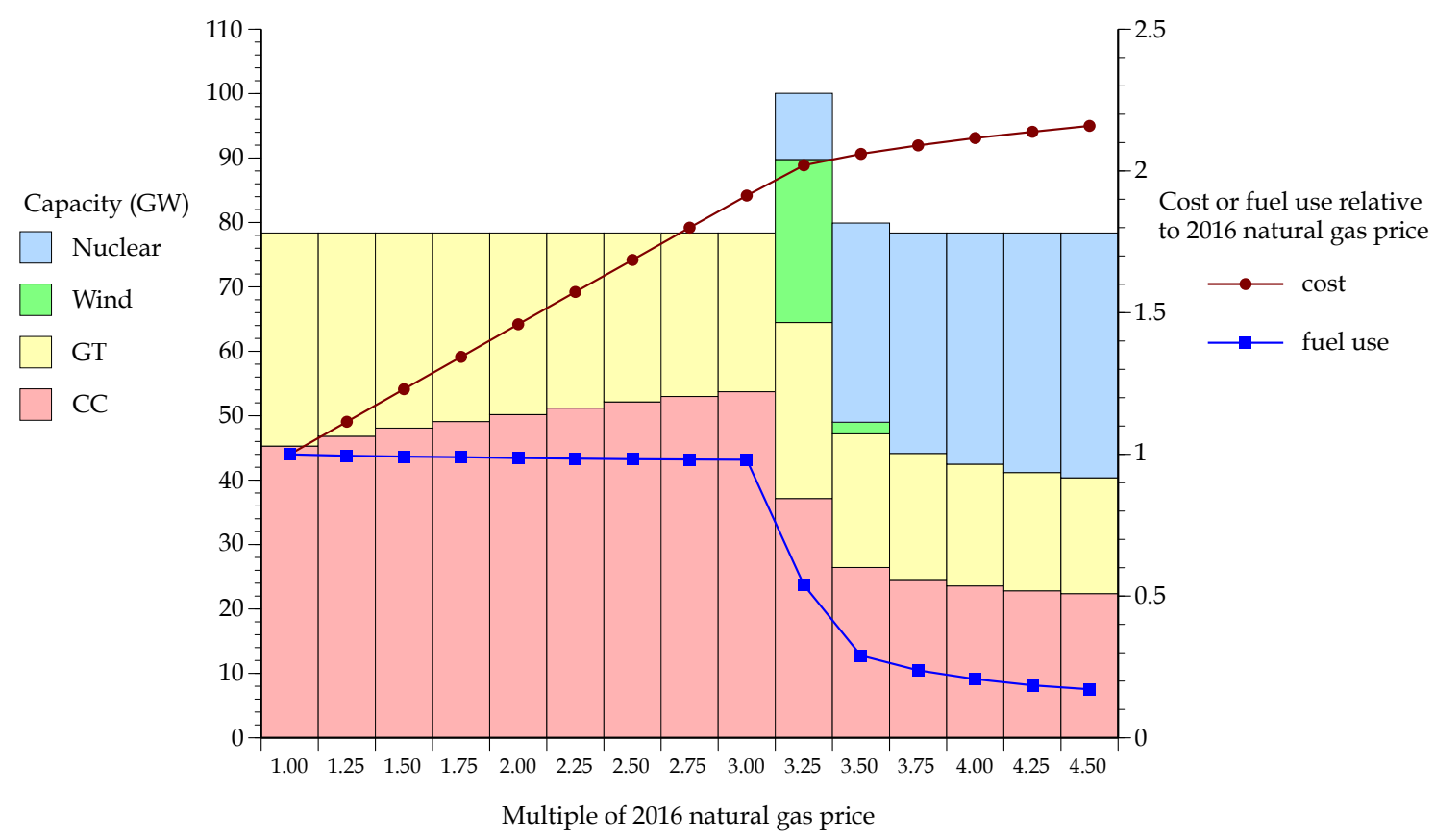

Figure 6: Optimal capacity mix, minimized cost and fuel use when $r=0.075$ 


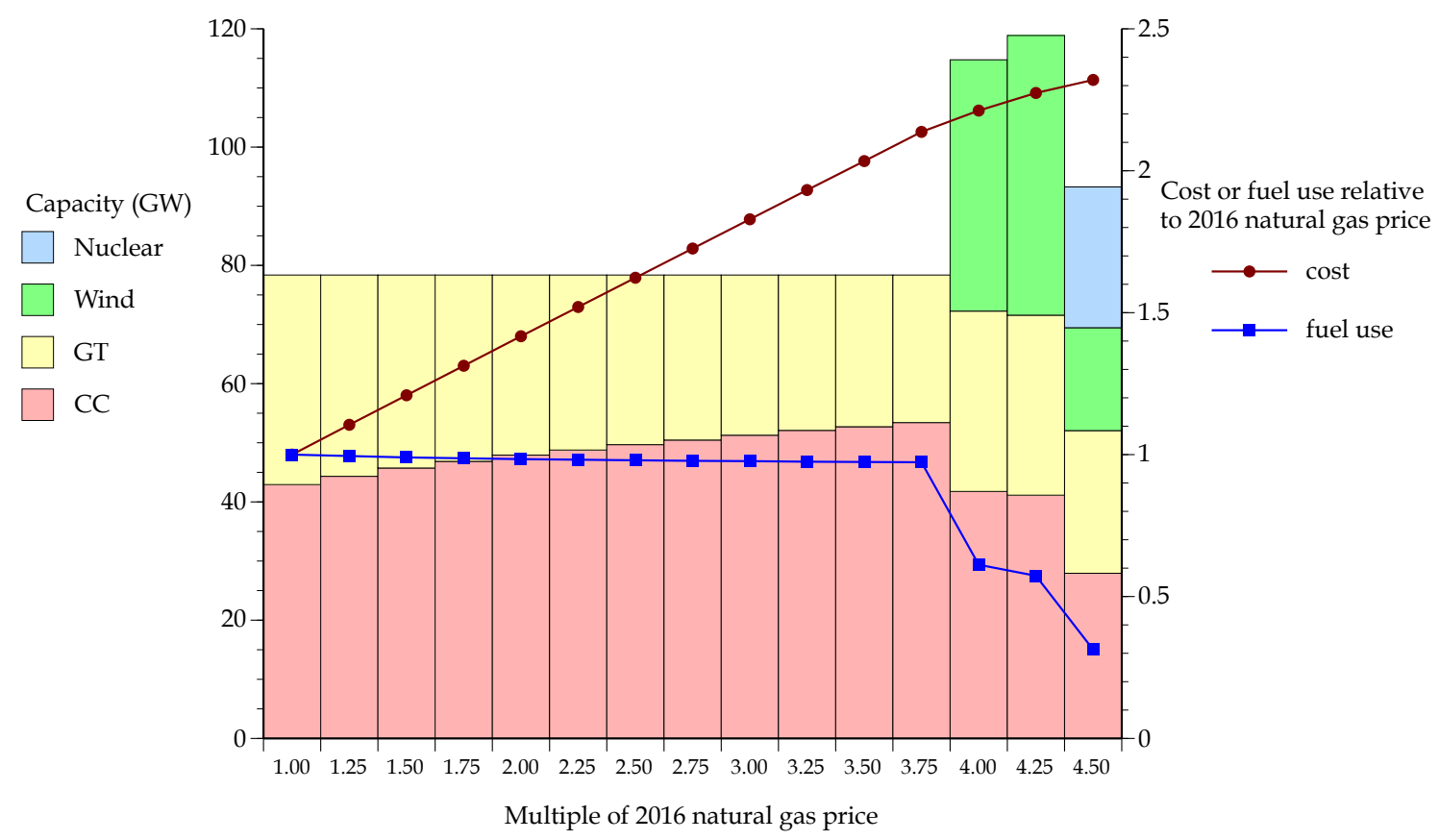

Figure 7: Optimal capacity mix, minimized cost and fuel use when $r=0.10$

Figures 5-7 graph the optimal generating capacities (measured in GW on the left hand axis) for a finer grid of natural gas prices than used in Table 4. Each figure also includes two line graphs (measured on the right hand axis). The top positively-sloped line gives minimized system annual cost as a ratio to minimized costs when the natural gas price equals the 2016 average (so the line starts at 1). The lower negatively-sloped line gives total fuel used relative to the fuel used in the minimum cost system when the natural gas price equals the 2016 average (so this line also starts at 1). The three figures correspond to the three different WACC values.

Prior to attaining the level where wind or nuclear displace natural gas, increases in the cost of natural gas have very little effect on the total amount of fuel used. A given percentage increase in the price of natural gas raises costs by around 40 times the percentage that it reduces natural gas use. An implication is that a tax on natural gas use, or on $\mathrm{CO}_{2}$ emissions, ${ }^{17}$ would raise electricity prices substantially while doing very little to reduce gas use until the tax rate was high enough to trigger the entry of wind, or especially nuclear, generation into the system.

Storage is included in the minimum cost systems in Figures 5-7 only when WACC is 5\% and the natural gas price is at least $\$ 11.57 / \mathrm{MMBTU}$ (4 times the 2016 price). ${ }^{18} \mathrm{~A}$ low WACC is required because storage is capital intensive. A high natural gas price also is needed, for

\footnotetext{
${ }^{17}$ According to EIA data, burning one MMBTU of natural gas emits about $53.07 \mathrm{~kg}$ of $\mathrm{CO}_{2}$. Hence, a tax of $\$ 10 /$ metric tonne of $\mathrm{CO}_{2}$ is equivalent to a tax on natural gas of around $534 / \mathrm{MMBTU}$ ( $18.3 \%$ of the 2016 price).

${ }^{18}$ For a WACC of $7.5 \%$, increasing $p_{N G}$ by even a factor of 5.5 is insufficient to make storage part of the costminimizing solution. However, increasing it by a factor of 6 - to more than $\$ 17 / \mathrm{MMBTU}$ - produces a minimum cost system with around $2.499 \mathrm{GW}$ of pumped storage. The result that storage is added after wind generation has been displaced reinforces the conclusion that the lowest cost long-run system (without fossil fuels) involves nuclear with storage.
} 


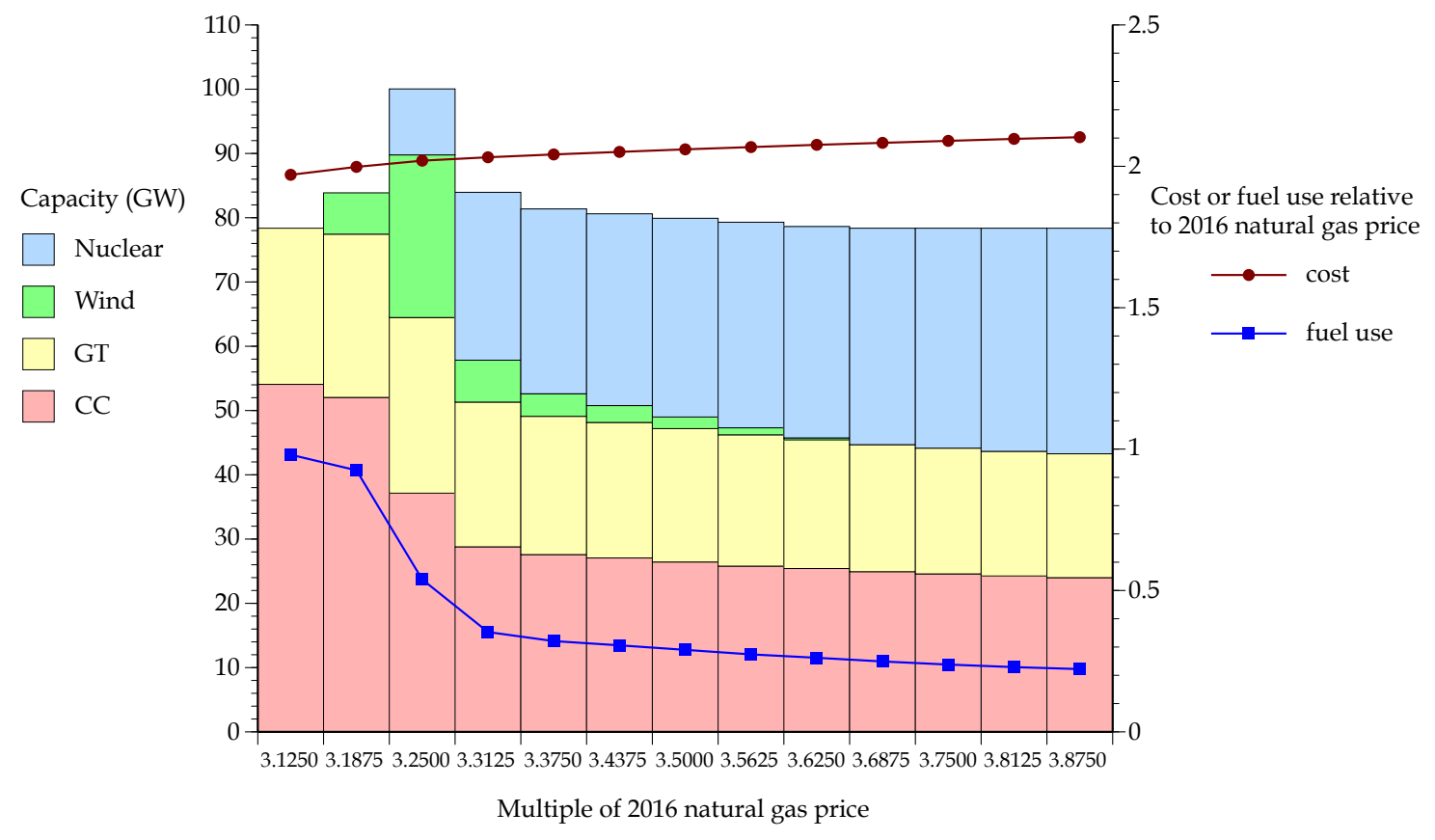

Figure 8: Transition away from natural gas when $r=0.075$

otherwise backup capacity can be provided by GT at much lower cost. ${ }^{19}$

Figures 8 and 9 focus on the transition away from natural gas as the natural gas price rises for a WACC of $7.5 \%$ and $10 \%$ respectively. These two figures present results for an even finer grid of natural gas prices, but over smaller ranges, than do the corresponding Figures 6 and 7 . The window of natural gas prices where wind is competitive appears limited, although the total amount of wind capacity included in the minimum cost system can be quite large. Table 5 shows that wind capacity is also part of the minimum cost system for a range of constraints on the amount of natural gas than can be used in the system while keeping WACC $=7.5 \%$ and $p_{N G}=2.89 /$ MMBTU. $^{20}$

In the cases where the transition is from natural gas to wind generation, the reduction in natural gas use is much smaller (on the order of $30 \%$ ) than when nuclear is introduced at higher gas prices (achieving a 50-65\% reduction in fuel use). The need to supply backup for wind generation implies that CC and GT capacities and load factors tend to be higher when there is wind and no nuclear than when there is nuclear and no wind. Wind therefore has a limited ability to reduce the demand for natural gas. The nuclear plants reduce gas use more effectively

\footnotetext{
${ }^{19}$ If large reductions in natural gas use are forced by constraining $E$ while nuclear is constrained to zero, storage is added. For example, for $r=0.075$ and $p_{N G}=2.89$, but with gas use constrained to 0.5 quads and nuclear constrained to zero, $8.561 \mathrm{GW}$ of storage is added to the system. For less severe constraints on natural gas use for example with gas use constrained to 1.0 quad - large amounts of wind capacity are added and a substantial amount of wind generation is "spilled". While this is costly, it is still less expensive than adding storage.

${ }^{20}$ It might be thought that a similar transition with positive wind capacity should occur when $r=0.05$. However, when $r=0.05, p_{N G}=2.89$ and $E$ is restricted slightly to 2.2 quads the cost-minimizing configuration has $0.655 \mathrm{GW}$ of nuclear and no wind. Not until $r$ is almost $7 \%$ does the cost-minimizing system when $E \leq 2.2$ quads include wind, and eb=ven then it is just $1.691 \mathrm{GW}$.
} 


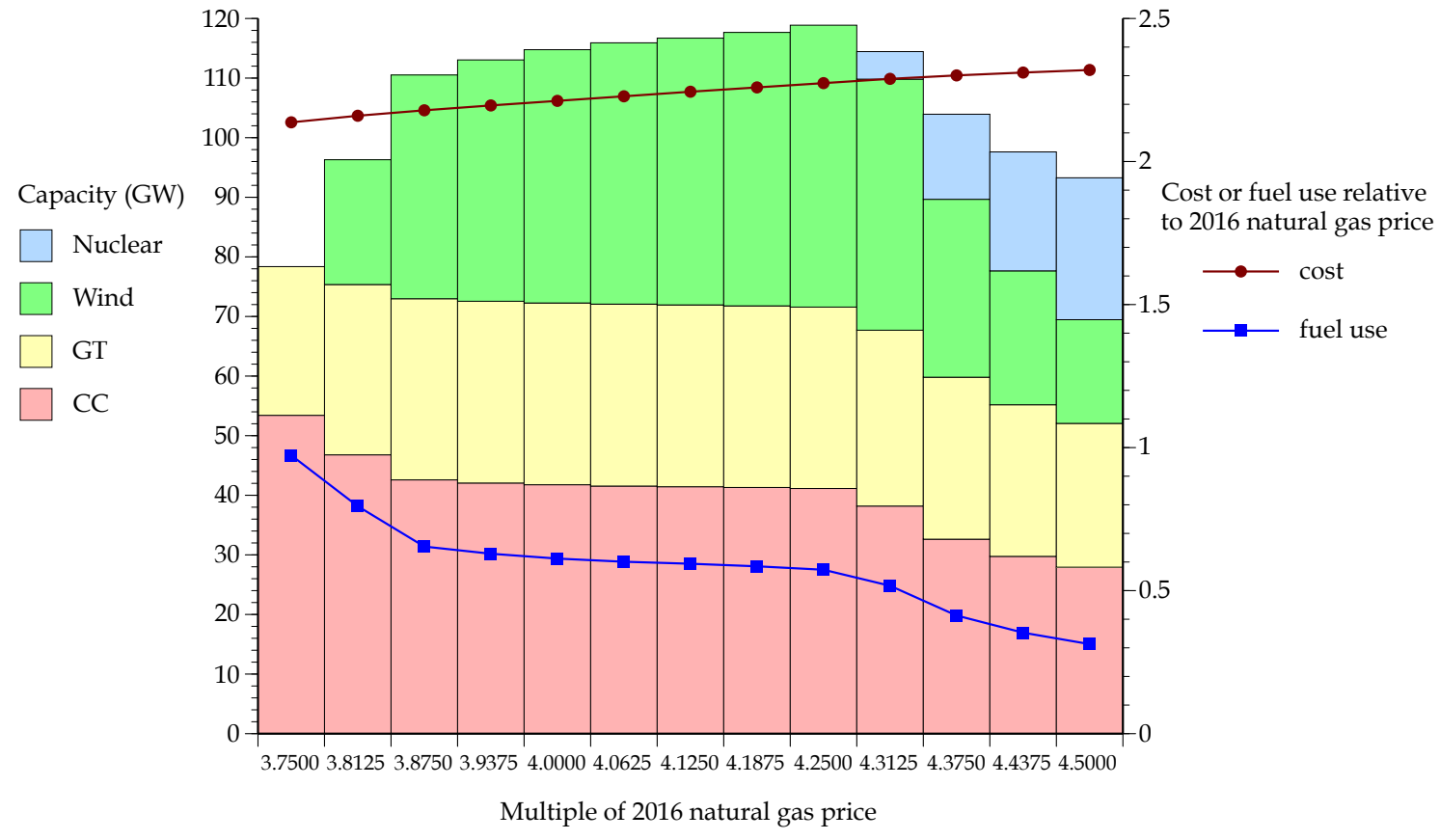

Figure 9: Transition away from natural gas when $r=0.10$

Table 5: Transitions from natural gas with constraints on gas use

\begin{tabular}{|c|c|c|c|c|c|}
\hline \multirow[b]{2}{*}{$r=.075, p_{N G}=2.89$} & \multicolumn{5}{|c|}{ Fuel use constraint $\left(10^{15} \mathrm{BTU}\right)$} \\
\hline & 2.279 & 2.0 & 1.5 & 1.0 & 0.5 \\
\hline Annual cost $(\$ \mathrm{~b})$ & 14.267 & 15.851 & 19.066 & 22.322 & 25.848 \\
\hline Average cost $(\Phi / \mathrm{kWh})$ & 4.06 & 4.51 & 5.43 & 6.35 & 7.36 \\
\hline $\mathrm{CC}$ capacity $(\mathrm{GW})$ & 45.289 & 50.175 & 42.599 & 32.453 & 23.915 \\
\hline GT capacity (GW) & 33.078 & 26.471 & 29.031 & 25.256 & 19.219 \\
\hline Wind capacity (GW) & 0 & 11.982 & 32.180 & 16.515 & 0 \\
\hline Nuclear capacity (GW) & 0 & 0 & 2.117 & 18.287 & 35.233 \\
\hline Pumped storage capacity (GW) & 0 & 0 & 0 & 0 & 0 \\
\hline CC load factor $(\%)$ & 83.67 & 69.90 & 60.90 & 52.39 & 34.59 \\
\hline GT load factor $(\%)$ & 6.39 & 2.59 & 2.58 & 2.72 & 2.56 \\
\hline Nuclear load factor (\%) & & & 90.08 & 90.03 & 88.68 \\
\hline
\end{tabular}


since they can reliably displace much more gas plant output. An implication is that, insofar as the negative externalities of electricity production are related to fossil fuel use, wind is far less effective at reducing those externalities than is nuclear. ${ }^{21}$

The analysis of the long-run systems implied that nuclear energy with storage provides the lowest cost long-run alternative to fossil fuels. Wind ended up being much more expensive than nuclear because it requires almost double the storage to make up for its intermittency, non-dispatchability, and generally negative correlation with system load. At a WACC of $7 \%$ or above, however, the cost minimizing solution over some range of natural gas prices involves wind and natural gas with no nuclear or storage. These results might appear contradictory. The explanation, however, is that wind needs much more backup capacity than does nuclear. When that backup is expensive storage, the system with wind has higher cost, but when it is less costly natural gas plant, the combined system including wind can have lower cost.

In the context of a dynamic optimization model of the transition process, a critical issue is the length of time that natural gas prices would lie in the range where wind is part of the costminimizing solution. That would, in turn, depend on the rate of growth in electricity demand and the elasticity of the natural gas supply curve. If the time interval during which wind is part of the cost-minimizing solution is shorter than 25 years, the lifetime of the wind generators would be shortened, raising their equivalent annual capital cost.

Figure 7 in particular also suggests that the range of natural gas prices where substantial wind capacity is part of the minimum cost system could be even shorter. Even if some wind generators would be used for some time, a large amount of wind capacity might have a very short life.

Where additional wind generation would be far from the load centers, required new transmission lines may also be under-utilized or even abandoned once the wind generation is itself later displaced. This also will be costly if the new lines are used only briefly.

Furthermore, while including wind in the system lowers cost over some ranges of natural gas prices, the cost difference may not be large. This is examined in Table 6, which contrasts cases where wind capacity is used when WACC is $7.5 \%$ or $10 \%$ with the outcome when wind capacity is constrained to be zero but $r$ and $p_{N G}$ keep the same values. For $r=0.075, p_{N G}=9.22$ (3.1875 times the 2016 price), Table 6 shows that, when wind capacity is constrained to zero, the minimum cost system becomes all natural gas. The annual cost rises by only $\$ 2.13$ million. When the natural gas price is raised further to $\$ 9.40$ (3.25 times the 2016 price), constraining

\footnotetext{
${ }^{21}$ This result is consistent with the observations of Green and Staffell [4] that the $11 \mathrm{GW}$ of wind and $30 \mathrm{GW}$ of solar that Germany added to its system between 2008 and 2013 merely offset the emissions from closing 8GW of nuclear stations in 2011.
} 
Table 6: Effects from constraining wind capacity to zero

\begin{tabular}{|c|c|c|c|c|c|c|}
\hline \multirow[b]{2}{*}{$r=.075$} & \multicolumn{2}{|c|}{$p_{N G}=9.22$} & \multicolumn{2}{|c|}{$p_{N G}=9.40$} & \multicolumn{2}{|c|}{$p_{N G}=10.12$} \\
\hline & $\omega$ free & $\boldsymbol{\omega}=\mathbf{0}$ & $\omega$ free & $\boldsymbol{\omega}=\mathbf{0}$ & $\omega$ free & $\omega=0$ \\
\hline Annual cost (\$b) & 28.505 & 28.507 & 28.824 & 28.863 & 29.385 & 29.386 \\
\hline Average cost $(\Phi / k W h)$ & 8.11 & 8.11 & 8.20 & 8.21 & 8.36 & 8.36 \\
\hline CC capacity (GW) & 52.040 & 54.188 & 37.144 & 28.732 & 26.436 & 26.202 \\
\hline GT capacity $(\mathrm{GW})$ & 25.405 & 24.179 & 27.325 & 21.171 & 20.750 & 20.371 \\
\hline Wind capacity (GW) & 6.428 & 0 & 25.308 & 0 & 1.806 & 0 \\
\hline Nuclear capacity (GW) & 0 & 0 & 10.265 & 28.465 & 30.922 & 31.794 \\
\hline Pumped storage capacity (GW) & 0 & 0 & 0 & 0 & 0 & 0 \\
\hline CC load factor $(\%)$ & 71.24 & 72.65 & 56.73 & 47.85 & 41.82 & 41.64 \\
\hline GT load factor $(\%)$ & 2.59 & 2.64 & 2.63 & 2.92 & 2.74 & 2.80 \\
\hline Nuclear load factor (\%) & & & 90.05 & 90.08 & 89.72 & 89.72 \\
\hline \multirow[t]{2}{*}{ Fuel used $\left(10^{15} \mathrm{BTU}\right)$} & 2.108 & 2.234 & 1.228 & 0.814 & 0.661 & 0.653 \\
\hline & \multicolumn{2}{|c|}{$p_{N G}=11.21$} & \multicolumn{2}{|c|}{$p_{N G}=11.57$} & \multicolumn{2}{|c|}{$p_{N G}=12.29$} \\
\hline$r=.10$ & $\omega$ free & $\boldsymbol{\omega}=\mathbf{0}$ & $\omega$ free & $\omega=0$ & $\omega$ free & $\omega=0$ \\
\hline Annual cost (\$b) & 34.440 & 34.580 & 34.964 & 35.389 & 35.950 & 36.301 \\
\hline Average cost $(\Phi / k W h)$ & 9.80 & 9.84 & 9.95 & 10.07 & 10.23 & 10.33 \\
\hline CC capacity (GW) & 42.583 & 53.660 & 41.770 & 54.001 & 41.139 & 27.147 \\
\hline GT capacity (GW) & 30.394 & 24.707 & 30.495 & 24.366 & 30.437 & 20.919 \\
\hline Wind capacity (GW) & 37.543 & 0 & 42.499 & 0 & 47.298 & 0 \\
\hline Nuclear capacity (GW) & 0 & 0 & 0 & 0 & 0 & 30.301 \\
\hline Pumped storage capacity (GW) & 0 & 0 & 0 & 0 & 0 & 0 \\
\hline CC load factor $(\%)$ & 60.74 & 73.26 & 57.85 & 72.87 & 54.93 & 44.70 \\
\hline GT load factor $(\%)$ & 2.74 & 2.83 & 2.65 & 2.71 & 2.55 & 2.92 \\
\hline Nuclear load factor (\%) & & & & & & 89.97 \\
\hline Fuel used $\left(10^{15} \mathrm{BTU}\right)$ & 1.503 & 2.236 & 1.407 & 2.234 & 1.317 & 0.724 \\
\hline
\end{tabular}

wind capacity to zero now results in a system with much more nuclear and an annual cost that is $\$ 38.75$ million higher. Increasing $p_{N G}$ further to $\$ 10.12$ (3.5 times the 2016 price), the increase in annual cost from constraining wind capacity to zero falls to just $\$ 1.41$ million.

When the WACC is raised to $10 \%$, the lower panel in Table 6 shows that the costs of the minimum cost system are more affected by constraining wind capacity to zero. When $p_{N G}=11.21$ (3.875 times the 2016 price), they increase by more than $\$ 140$ million, when $p_{N G}=11.57$ (4 times the 2016 price) by almost $\$ 425$ million and when $p_{N G}=12.29$ (4.25 times the 2016 price) by more than $\$ 350$ million. Nevertheless, these costs are quite small if additional wind capacity requires upgrading or extending the transmission system. Recall that the CREZ lines in Texas cost around $\$ 7$ billion. ${ }^{22}$

It might be thought that constraining wind capacity to zero, and increasing the longevity of the all natural gas system, would result in more natural gas use and higher emissions. In the examples in Table 6, using all natural gas instead of wind plus gas when $r=0.075, p_{N G}=9.22$ does indeed consume an additional 0.126 quads of natural gas per year. However, the natural

\footnotetext{
${ }^{22}$ Ancillary service costs could also differ in the two systems since GT capacity is being used differently.
} 
gas plus nuclear system when $r=0.075, p_{N G}=9.40$ consumes 0.414 fewer quads of natural gas per year. When $r=0.10$, the increased gas consumption when $p_{N G}=11.21$ is 0.733 quads and when $p_{N G}=11.57,0.828$ quads, but when $p_{N G}=12.29$, it falls by 0.593 quads.

More to the point, since natural gas is such a clean burning fossil fuel, the main issue that its consumption raises is the emission of $\mathrm{CO}_{2}$. The externality in this case is, however, a stock one, not a flow one. The gradual accumulation of $\mathrm{CO}_{2}$ in the atmosphere, not the emissions in any one year, is associated with surface temperature changes and other effects on climate. In that regard, since the cost of supply increases with depletion, the ultimate consumption of fossil fuel depends mostly on the cost of the non-fossil energy supply system. Greater consumption in years prior to transition to the non-fossil fuel system will lead to more rapid depletion and higher price increases. Hence, it will hasten the time when fossil fuels are replaced. In short, prolonging the persistence of an all natural gas system and then hastening the build up of nuclear by constraining the use of wind capacity would likely have only minor effects on the cumulative use of natural gas.

Greater uncertainty about the potential marginal net damage from $\mathrm{CO}_{2}$ emissions may also favor the use of more nuclear power in the short term by increasing its option value. In particular, if new information reveals a greater urgency to transition away from fossil fuels for environmental reasons, this will be much easier if there is more nuclear and less wind capacity in the system.

\section{Concluding remarks}

The ERCOT ISO in Texas can be used to explore the likely costs of displacing fossil fuels from electricity supply. The ERCOT system has only weak connections with neighboring systems and, except for emergencies, operates essentially as a stand-alone system. It also has a substantial amount of wind capacity operating at a relatively high average load factor. Hence, it provides a realistic example of the operation and costs of a system dominated by wind generation.

Combining data from ERCOT with cost estimates of different technologies from the EIA, we calculated the costs of satisfying the 2016 ERCOT load using different combinations of wind, natural gas, and nuclear generation together with pumped storage. We found that, for the longrun system where the 2016 ERCOT load is supplied by either wind or nuclear supplemented with storage, the system with wind is much more costly than the one with nuclear. The main reason is that the system with wind requires almost double the amount of electricity storage, which is very expensive. Even at a real discount rate of $10 \%$, which is close to the real return on equity alone for an electric utility, and which normally would be expected to favor wind over nuclear, the system with wind remained more than $25 \%$ more expensive. On the other hand, we 
also found that for a discount rate of around $7 \%$ or higher, and an intermediate range of natural gas prices or moderate quantitative restrictions on annual natural gas use, the wind plus natural gas system was less costly than the nuclear plus natural gas one.

While the two sets of results may appear contradictory, they are actually consistent. The reason is that wind needs much more complementary generating capacity than nuclear as a result of its high variability and slightly negative correlation with system load. When that additional capacity is relatively low cost gas generation, the hybrid system with wind is less expensive when compared to the nuclear plus gas system. When the complementary capacity is high cost storage, however, the wind system becomes much more expensive.

When nuclear power is a better long-run option than wind generation, nuclear might also be a better short-run investment. Additional wind capacity slows the adoption of nuclear as natural gas prices rise. The reason is that wind tends to supply more output in low demand nighttime hours, while its high variability increases the variability of the net load on the thermal system. Both factors make it much harder for base load technologies like nuclear to cover their costs.

We also found that in circumstances where wind capacity was part of the cost-minimizing system, constraining it to zero raises costs by only very modest amounts. The use of natural gas alone persists for slightly longer, but the build-up of nuclear capacity occurs more rapidly. The cost savings from allowing wind to displace natural gas or nuclear in the interim are so small that they could easily be exceeded by the cost of building additional transmission capacity to connect remote wind farms with loads. Furthermore, if the period during which wind is part of the minimum cost system is short, wind generators and associated infrastructure might be used for less time than their normal lifespans. If so, this would further raise effective annual costs and make the wind generation less competitive.

Nuclear power has additional value in a world where we desire to limit cumulative $\mathrm{CO}_{2}$ emissions from fossil fuel use for environmental reasons. Since nuclear with storage has lower costs in the long run than wind with storage, the cost of fossil fuel energy, and hence the total amount that is mined, does not have to rise as much before fossil fuels are displaced. Less fossil fuel ultimately will be burned, implying cumulative $\mathrm{CO}_{2}$ emissions also will be lower. Finally, if there is substantial uncertainty about the environmental effects of fossil fuel use, nuclear also has a higher option value than wind. If new information reveals that more drastic reductions in fossil fuel use are required, they can be achieved in a shorter period of time when there is more nuclear capacity in the system. 


\section{References}

[1] Boßmann, T. and Iain Staffell (2015) "The shape of future electricity demand: Exploring load curves in 2050s Germany and Britain." Energy, 90: 1317-1333.

[2] Cullen, Joseph (2013) "Measuring the Environmental Benefits of Wind-Generated Electricity." American Economic Journal: Economic Policy, 5(4): 107-133.

[3] Delucchi, Mark A. and Mark Z. Jacobson (2011). "Providing all global energy with wind, water, and solar power, Part II: Reliability, system and transmission costs, and policies." Energy Policy, 39: 1170-1190.

[4] Green, Richard and Iain Staffell (2016) "Electricity in Europe: exiting fossil fuels?" Oxford Review of Economic Policy, 32(2): 282-303.

[5] Green, Richard and Nicholas Vasilakos (2011) "The Long-term Impact of Wind Power on Electricity Prices and Generating Capacity." Centre for Competition Policy, University of East Anglia, CCP Working Paper 11-4.

[6] Green, Richard and Nicholas Vasilakos (2012) "Storing wind for a rainy day: What kind of electricity does Denmark export?" The Energy Journal, 33(3):1-22.

[7] Grubler, Arnulf (2010) "The costs of the French nuclear scale-up: A case of negative learning by doing." Energy Policy, 38: 5174-5188.

[8] Hartley, Peter R., Kenneth B. Medlock III, Ted Temzelides and Xinya Zhang (2016) "Energy Sector Innovation and Growth." The Energy Journal, 37 (1): 233-258.

[9] Hartley, Peter R. and Kenneth B. Medlock III (2017). "The Valley of Death for New Energy Technologies." The Energy Journal, 38(3): 3361.

[10] Jacobson, Mark Z. and Mark A. Delucchi (2011). "Providing all global energy with wind, water, and solar power, Part I: Technologies, energy resources, quantities and areas of infrastructure, and materials." Energy Policy, 39: 1154-1169.

[11] Lokhov, Alexy (2011). "Load-following with nuclear power plants." NEA update, NEA News, Nuclear Energy Agency, 29.2:18-20.

[12] Luo, Xing, Jihong Wang, Mark Dooner and Jonathan Clarke (2015). "Overview of current development in electrical energy storage technologies and the application potential in power system operation." Applied Energy, 137: 511-536. 
[13] Qvist, Staffan A. and Barry W. Brock (2015) "Potential for Worldwide Displacement of Fossil-Fuel Electricity by Nuclear Energy in Three Decades Based on Extrapolation of Regional Deployment Data." PLoS ONE, 10(5): e0124074.

[14] Schoenung, Susan M. and William V. Hassenzahl (2003). "Long- vs. Short-Term Energy Storage Technologies Analysis: A Life-Cycle Cost Study." A Study for the DOE Energy Storage Systems Program, Sandia National Laboratories Sandia Report SAND2003-2783

[15] Trainer, Ted (2012). "A critique of Jacobson and Delucchi's proposals for a world renewable energy supply." Energy Policy, 44: 476-481. 
Editor, UWA Economics Discussion Papers:

Sam Hak Kan Tang

University of Western Australia

35 Sterling Hwy

Crawley WA 6009

Australia

Email: ecoadmin@biz.uwa.edu.au

The Economics Discussion Papers are available at:

1980 - 2002: http://ecompapers.biz.uwa.edu.au/paper/PDF\%20of\%20Discussion\%20Papers/

Since 2001: $\quad$ http://ideas.repec.org/s/uwa/wpaper1.html

Since 2004: $\quad$ http://www.business.uwa.edu.au/school/disciplines/economics

\begin{tabular}{|c|c|c|}
\hline \multicolumn{3}{|c|}{ ECONOMICS DISCUSSION PAPERS - 2016} \\
\hline $\begin{array}{l}\text { DP } \\
\text { NUMBER }\end{array}$ & AUTHORS & TITLE \\
\hline 16.01 & $\mathrm{Xu}, \mathrm{R} ., \mathrm{Wu}, \mathrm{Y}$. and Luan, J. & $\begin{array}{l}\text { ANALYSIS OF FARMERS' WILLINGNESS TO ADOPT } \\
\text { GENETICALLY MODIFIED INSECT-RESISTANT RICE IN } \\
\text { CHINA }\end{array}$ \\
\hline 16.02 & $\begin{array}{l}\text { Lia, Y., Fan, J., Zhao, D., Wu, Y. and } \\
\text { Li, J. }\end{array}$ & $\begin{array}{l}\text { TIERED GASOLINE PRICING: A PERSONAL CARBON } \\
\text { TRADING PERSPECTIVE }\end{array}$ \\
\hline 16.03 & Clements, K.W., Lan, Y. and Si, J. & UNCERTAINTY IN CURRENCY MISPRICING \\
\hline 16.04 & Parsons, C. and Vézina, P.L. & $\begin{array}{l}\text { MIGRANT NETWORKS AND TRADE:THE VIETNAMESE } \\
\text { BOAT PEOPLE AS A NATURAL EXPERIMENT }\end{array}$ \\
\hline 16.05 & Chang, S., Connelly, R. and Ma, P. & $\begin{array}{l}\text { WHAT WILL YOU DO IF I SAY ‘I DO’?: THE EFFECT OF } \\
\text { THE SEX RATIO ON TIME USE WITHIN TAIWANESE } \\
\text { MARRIED COUPLES }\end{array}$ \\
\hline 16.06 & $\mathrm{Yu}, \mathrm{F}$. and $\mathrm{Wu}, \mathrm{Y}$. & $\begin{array}{l}\text { BIASES IN PATENT EXAMINATION AND FIRMS' } \\
\text { RESPONSES: EVIDENCE FROM THE } \\
\text { PHARMACEUTICAL INDUSTRY }\end{array}$ \\
\hline 16.07 & $\begin{array}{l}\text { Fan, J., Li, J., Wu, Y., Wang, S. and } \\
\text { Zhao, D. }\end{array}$ & $\begin{array}{l}\text { THE EFFECTS OF ALLOWANCE PRICE ON ENERGY } \\
\text { DEMAND UNDER A PERSONAL CARBON TRADING } \\
\text { SCHEME }\end{array}$ \\
\hline 16.08 & Golley, J., Tyers, R. and Zhou, Y. & $\begin{array}{l}\text { CONTRACTIONS IN CHINESE FERTILITY AND } \\
\text { SAVINGS: LONG RUN DOMESTIC AND GLOBAL } \\
\text { IMPLICATIONS }\end{array}$ \\
\hline 16.09 & McGrath, G. and Neill, K. & $\begin{array}{l}\text { FOREIGN AND DOMESTIC OWNERSHIP IN WESTERN } \\
\text { AUSTRALIA'S GAS MARKET }\end{array}$ \\
\hline 16.10 & Clements, K.W. and Si, J. & SIMPLIFYING THE BIG MAC INDEX \\
\hline 16.11 & Priyati, R.Y. and Tyers, R. & $\begin{array}{l}\text { PRICE RELATIONSHIPS IN VEGETABLE OIL AND } \\
\text { ENERGY MARKETS }\end{array}$ \\
\hline 16.12 & Wu, J., Wu, Y. and Wang, B. & $\begin{array}{l}\text { THE GREENNESS OF CHINESE CITIES: CARBON } \\
\text { DIOXIDE EMISSION AND ITS DETERMINANTS }\end{array}$ \\
\hline 16.13 & $\begin{array}{l}\text { Arslan, C., Dumont, J.C., Kone, Z., } \\
\text { Özden, Ç., Parsons, C. and } \\
\text { Xenogiani, T. }\end{array}$ & $\begin{array}{l}\text { INTERNATIONAL MIGRATION TO THE OECD IN THE } \\
\text { TWENTY-FIRST CENTURY }\end{array}$ \\
\hline 16.14 & Tomioka, K. and Tyers, R. & $\begin{array}{l}\text { HAS FOREIGN GROWTH CONTRIBUTED TO } \\
\text { STAGNATION AND INEQUALITY IN JAPAN? }\end{array}$ \\
\hline 16.15 & Donovan, J. and Hartley, P. & $\begin{array}{l}\text { RIDING THE IRON ORE CYCLE: ACTIONS OF } \\
\text { AUSTRALIA'S MAJOR PRODUCERS }\end{array}$ \\
\hline 16.16 & Czaika, M. and Parsons, C. & $\begin{array}{l}\text { HIGH-SKILLED MIGRATION IN TIMES OF GLOBAL } \\
\text { ECONOMIC CRISIS }\end{array}$ \\
\hline
\end{tabular}




\begin{tabular}{|l|l|l|}
\hline 16.17 & Lefroy, T., Key, J. and Kingwell, R. & $\begin{array}{l}\text { A LONGITUDINAL EXAMINATION OF BROADACRE } \\
\text { FARM SIZE AND PERFORMANCE IN WESTERN } \\
\text { AUSTRALIA }\end{array}$ \\
\hline 16.18 & Arthmar, R. and McLure, M. & $\begin{array}{l}\text { SRAFFA, MYRDAL AND THE 1961 SÖDERSTRÖM GOLD } \\
\text { MEDAL }\end{array}$ \\
\hline 19.19 & Azwar, P. and Tyers, R. & $\begin{array}{l}\text { POST-GFC EXTERNAL SHOCKS AND INDONESIAN } \\
\text { ECONOMIC PERFORMANCE }\end{array}$ \\
\hline 19.20 & Chen, A. and Groenewold, N. & $\begin{array}{l}\text { OUTPUT SHOCKS IN CHINA: DO THE DISTRIBUTIONAL } \\
\text { EFFECTS DEPEND ON THE REGIONAL SOURCE? }\end{array}$ \\
\hline 19.21 & Wu, Y., Zhu, X. and Groenewold, N. & $\begin{array}{l}\text { THE DETERMINANTS AND EFFECTIVENESS OF } \\
\text { INDUSTRIAL POLICY IN CHINA: A STUDY BASED ON } \\
\text { FIVE-YEAR PLANS }\end{array}$ \\
\hline 16.22 & Liu, H. & $\begin{array}{l}\text { THE INCOME AND PRICE SENSITIVITY OF DIETS } \\
\text { GLOBALLY }\end{array}$ \\
\hline 16.23 & Asano, A., Neill, K. and Yamazaki, S. & $\begin{array}{l}\text { DECOMPOSING FISHING EFFORT: MODELLING THE } \\
\text { SOURCES OF INEFFICIENCY IN A LIMITED-ENTRY } \\
\text { FISHERY }\end{array}$ \\
\hline 16.24 & Golley, J., Tyers, R. and Zhou, Y. & $\begin{array}{l}\text { FERTILITY AND SAVINGS CONTRACTIONS IN CHINA: } \\
\text { LONG-RUN GLOBAL IMPLICATIONS }\end{array}$ \\
\hline 16.25 & Taylor, G., Tyers, R. & $\begin{array}{l}\text { Secular Stagnation: Determinants and Consequences for } \\
\text { Australia }\end{array}$ \\
\hline
\end{tabular}

\begin{tabular}{|l|l|l|}
\hline \multicolumn{2}{|c|}{ ECONOMICS DISCUSSION PAPERS - 2017 } \\
\hline $\begin{array}{c}|c| \\
\text { DP } \\
\text { NUMBER }\end{array}$ & \multicolumn{1}{|c|}{ AUTHORS } & \multicolumn{1}{c|}{ TITLE } \\
\hline 17.01 & Tyers, R. and Zhou, Y. & $\begin{array}{l}\text { AUTOMATION AND INEQUALITY WITH TAXES AND } \\
\text { TRANSFERS }\end{array}$ \\
\hline 17.02 & Ye, L. and Robertson, P. & $\begin{array}{l}\text { HITTING THE GREAT WALL: RURAL-URBAN } \\
\text { MIGRATION AND CHINA'S GROWTH SLOWDOWN }\end{array}$ \\
\hline 17.03 & Ye, L. and Robertson, P. & $\begin{array}{l}\text { MIGRATION AND GROWTH IN CHINA: A SCEPTICAL } \\
\text { ASSESSMENT OF THE EVIDENCE }\end{array}$ \\
\hline 17.04 & Clements, K. Si, J. and Vo, L. & $\begin{array}{l}\text { FOOD AND AGRICULTURAL PRICES ACROSS } \\
\text { COUNTRIES AND THE LAW OF ONE PRICE }\end{array}$ \\
\hline 17.05 & $\begin{array}{l}\text { Chen, M., Clements, K., Gao, G. and } \\
\text { Si, J. }\end{array}$ & $\begin{array}{l}\text { THREE FACTS ABOUT WORLD METAL PRICES } \\
\text { Cornes, R., Fiorini, L. and }\end{array}$ \\
\hline 17.06 & Maldonado, W. & $\begin{array}{l}\text { EXPECTATIONAL STABILITY IN AGGREGATIVE } \\
\text { GAMES }\end{array}$ \\
\hline 17.07 & $\begin{array}{l}\text { THE COST OF DISPLACING FOSSIL FUELS: SOME } \\
\text { EVIDENCE FROM TEXAS }\end{array}$ \\
\hline 17.08 & Shehabi, M. R. & $\begin{array}{l}\text { GSSESSING KUWAITI ENERGY PRICINING REFORMS } \\
\text { INTERACTION OR UNILATERAL GAINS? }\end{array}$ \\
\hline 17.09 & Perdana, S. and Tyers, R. & \\
\hline
\end{tabular}

